\title{
Case Study of the Leeside Mesolow and Mesocyclone in TAMEX
}

\author{
Chung-Chieh WANG \\ Department of Environmental Management, Jin-Wen Institute of Technology, Taipei, Taiwan, Republic of China \\ George TAI-JEN Chen \\ Department of Atmospheric Sciences, National Taiwan University, Taipei, Taiwan, Republic of China
}

(Manuscript received 16 February 2001, in final form 25 March 2002)

\begin{abstract}
An observational study was performed on a leeside mesolow case that occurred 8 June 1987 during the Taiwan Area Mesoscale Experiment (TAMEX). The case developed as prevailing west-southwest winds strengthened and interacted with the terrain of Taiwan, with a Froude number $(\mathrm{Fr}=U / N h)$ increasing from below 0.3 to over 0.5. A quasi-stationary mesolow formed to the southeast of Taiwan with no closed circulation through most of its 13-h life stages until passage of the Mei-yu front. A stationary and localized mesovortex also formed about $90 \mathrm{~km}$ southwest of the low center, but little adjustment was observed between the mesolow and the vortex.

Results suggest that airflow at lower levels was blocked and moved around the terrain of the southern Central Mountain Range (CMR). This led to the formation of low-level jets (LLJs) both to the northwest and southeast of Taiwan. The latter branch provided shear vorticity in the background region of the vortex. Air parcels at higher levels, on the other hand, tended to climb over the mountain and caused precipitation on the windward slope, then subsided at the lee side. The subsidence produced the mesolow through adiabatic warming and drying, which was strongest between 1 and $2 \mathrm{~km}$. Latent heat release at the windward side was estimated to contribute a maximum of about $55 \%-60 \%$ of the total warming. Eventually, as the Mei-yu front moved southward along the eastern coast of Taiwan, the mesolow merged with the front and transformed into a migratory mesocyclone along the front.
\end{abstract}

\section{Introduction}

During the Mei-yu season (May to June), shallow and short-lived mesolows often form to the southeast, northwest, and southwest of Taiwan, and affect the distribution of precipitation. Those to the southeast appear at the lee side of the Central Mountain Range (CMR) when a Mei-yu front approaches and prevailing southwesterly wind intensifies and interacts with the terrain (Kuo and Chen 1990; Chen 1992a). Mesolows have a horizontal scale about $150-200 \mathrm{~km}$, a vertical extent from the surface to about $1500 \mathrm{~m}$, an average life span of roughly $12 \mathrm{~h}$, and a sea level pressure perturbation of $3-5 \mathrm{hPa}$.

As airflow encounters an obstacle such as a mountain, one parameter controlling the overall flow structure is the Froude number $(\mathrm{Fr}=U / N h$, where $U$ is wind speed perpendicular to mountain, $h$ is terrain height, and $N$ is Brunt-Väisälä frequency where $N^{2}=(g / \theta)(d \theta / d z)$. In a low-Fr regime where airflow tends to be blocked, Forbes et al. (1987) and Bell and Bosart (1988) showed that

Corresponding author address: Dr. George Tai-Jen Chen, Department of Atmospheric Sciences, National Taiwan University, 61, Ln. 144, Sec. 4, Keelung Rd., Taipei 10772, Taiwan.

E-mail: george@george2.as.ntu.edu.tw airflow moves around the Appalachian Mountains of the United States when Fr is less than 0.3-0.4. Smolarkiewicz et al. (1988) found that a cloud band forms due to airflow convergence at the windward side of Hawaii when $\mathrm{Fr}$ is smaller than 1, but orographic precipitation occurs instead when Fr exceeds 1. For larger Fr values, flow tends to rise over the terrain. In their study, Manins and Sawford (1982) suggested that airflow climbs over a small hill when $\mathrm{Fr}>1.6$. Besides the Froude number, an additional control parameter of stratified flow past an isolated obstacle is the Rossby number (Ro $=U / f L$, where $f$ is the Coriolis parameter and $L$ is the characteristic length), which measures the relative importance of inertial and Coriolis forces. The Coriolis effect enhances leftward deflection of airflow at the windward side and shifts the mesolow to the right at the lee side, and becomes small as Ro increases (e.g., Lin et al. 1992; Peng et al. 1995). Based on linear mountain wave theory, as stratified air flows over a terrain, upward-propagating inertia-gravity waves are produced, and a pair of high-low pressure couplets appear at the windward side and the lee side through adiabatic warming and cooling, respectively (e.g., Smith 1980, 1982). When the prevailing wind intensifies, not only does Fr increase, allowing the flow to ascend the obstacle, but Ro 
also increases, making the flow more wavelike. At a low Rossby number, the flow is fore-and-aft symmetric and there is no tendency to form a leeside mesolow, at least at steady state. The high-low pressure couplet is then a consequence of the wave part of the disturbance, which becomes more pronounced as Ro increases. If saturation were achieved during the forced uplift along the windward slope, latent heat release would also enhance the mesolow at the lee side. This formation mechanism of adiabatic subsidence is consistent with the warm and dry characteristics found in mesolows to the southeast of Taiwan (e.g., Chen 1991).

The problem of lee vortex formation has also been studied by a number of researchers through theoretical analysis (Smith 1989; Schär and Smith 1993), laboratory experiment (e.g., Hunt and Snyder 1980), and numerical simulation for different Fr regimes (Smolarkiewicz and Rotunno 1989; Reisner and Smolarkiewicz 1994; Rotunno et al. 1999). Studies utilizing both observations and models, such as Crook et al. (1990), Lee et al. (1998), Davis (1997), are also found in the literature. Field campaigns are often needed to provide data at sufficient resolution to test theories and verify numerical model predictions, such as the Olympex Experiment (e.g., Ferber and Mass 1990), the Pyreenees Experiment (PYREX; e.g., Georgelin et al. 1996), and more recently the Mesoscale Alpine Programme (MAP; Bougeault et al. 2001).

For the Taiwan area, the 13 Intensive Observing Periods (IOPs) in the Taiwan Area Mesoscale Experiment (TAMEX) held May-June 1987 provide a unique opportunity to examine a variety of mesoscale phenomena during Mei-yu season, including the mesolow (Kuo and Chen 1990). The case of a lee vortex observed in IOP2 (17 May) has been studied by Lin et al. (1992) with the Colorado State University (CSU) Regional Atmospheric Modeling System (RAMS), and by Sun and Chern (1993) with the Purdue University mesoscale model. These and other studies (e.g., Chen 1991, 1992b) show that the leeside mesolows are not necessarily associated with a vortex, and the two can be quite independent. The detailed evolution of a mesolow/lee vortex and the accompaning flow structure in a real case, however, have not been well documented in the open literature from an observational standpoint. The purpose of the present paper, therefore, is to document a mesolow case in greater detail using TAMEX data, and to investigate the mechanism for its formation and maintenance. The case selected was observed to the southeast of Taiwan during IOP-8 7-8 June 1987 under prevailing southwesterly flow. Except for the analysis, the effect of latent heat release is estimated, and some related problems such as vorticity generation are also discussed.

\section{Data and analysis}

Data used in the present study include 12-hourly weather charts at mandatory levels generated by TA-
MEX program, hourly TAMEX original surface station plots (Wang 1990), hourly surface network data in Taiwan area (including ship observations), and 3-hourly sounding/upper-level wind data (or 6-hourly depending on data availability) from 7 to 8 June 1987 . The terrain of Taiwan and locations of various stations are plotted in Fig. 1.

Following the definition by Chen (1991), a mesolow is considered present when the sea level pressure (SLP) difference between Kaoshiung (46744) in southwestern Taiwan and Taitung (46766) in southeastern Taiwan (see Fig. 1 for locations) is greater than $1.5 \mathrm{hPa}$ for at least $6 \mathrm{~h}$. A mesovortex is considered present when a closed circulation can be analyzed in the wind field, while a mesocyclone is defined if both mesolow and mesovortex exist and are collocated. Also following Chen (1991), three life stages (intensification, mature, and weakening stages) with a total life span of $13 \mathrm{~h}$, were identified for the present case, and are shown in Fig. 2. The Kaoshiung minus Taitung SLP (with mean May-June diurnal cycle removed) increased from $1 \mathrm{hPa}$ through the intensification stage (2000 UTC 7 June to 0000 UTC 8 June; denoted by "A"), remained at about 2 to $3 \mathrm{hPa}$ in the mature stage (0000 to 0430 UTC 8 June; "B"), and then decreased to below $1.5 \mathrm{hPa}$ in the weakening stage (0430 to 0900 UTC; "C"). The period between 1000 and 1900 UTC 7 June also met the requirement of a mesolow, but this earlier event will not be discussed.

Surface mesoscale analyses of SLP and streamline were performed, and time-height cross sections at three sounding stations were constructed for meteorological parameters of interest: Makung $\left(46734 ; 23.6^{\circ} \mathrm{N}\right.$, $119.6^{\circ} \mathrm{E}$ ) over the Taiwan Strait, Tungkang (46747; $22.5^{\circ} \mathrm{N}, 120.5^{\circ} \mathrm{E}$ ) along the southwestern coast, and Lutao $\left(46780 ; 22.7^{\circ} \mathrm{N}, 121.5^{\circ} \mathrm{E}\right)$ to the southeast of Taiwan (see Fig. 1 for locations). Using wind components perpendicular to the terrain (assuming an orientation of $15^{\circ}$ ), upstream Fr and Ro below $3 \mathrm{~km}$ were calculated using sounding data from Jaohwa (RCJH; $21.7^{\circ} \mathrm{N}$, $119.2^{\circ} \mathrm{E}$ ) and using a mountain height of $2 \mathrm{~km}$ and a characteristic width of $70 \mathrm{~km}$. The height is very close to the averaged terrain height of $2055 \mathrm{~m}$ that would be faced by a southwesterly flow $\left(225^{\circ}\right)$, computed from 1 $\mathrm{km}$ by $1 \mathrm{~km}$ digitized elevation data. The $70 \mathrm{~km}$ was estimated from the width of the topography over the envelope of the 2-km-averaged terrain height along the flow direction. The resultant Fr and Ro values at different times in the life stages are presented in Table 1, while vertical profiles of horizontal wind at Jaohwa from 1800 UTC 7 June to 1200 UTC 8 June are shown in Fig. 3. The southwesterly wind was quite uniform in the lower troposphere, and strengthened gradually through the stages (marked with $\mathrm{A}, \mathrm{B}$, and $\mathrm{C}$ ), from about $7.5-10 \mathrm{~m} \mathrm{~s}^{-1}$ to $13-15 \mathrm{~m} \mathrm{~s}^{-1}$ (Fig. 3). The prevailing wind direction also turned slowly from southwest to nearly west, and became more perpendicular to the terrain. Reflecting this overall strengthening of prevailing wind, the Fr value was below 0.3 in the inten- 


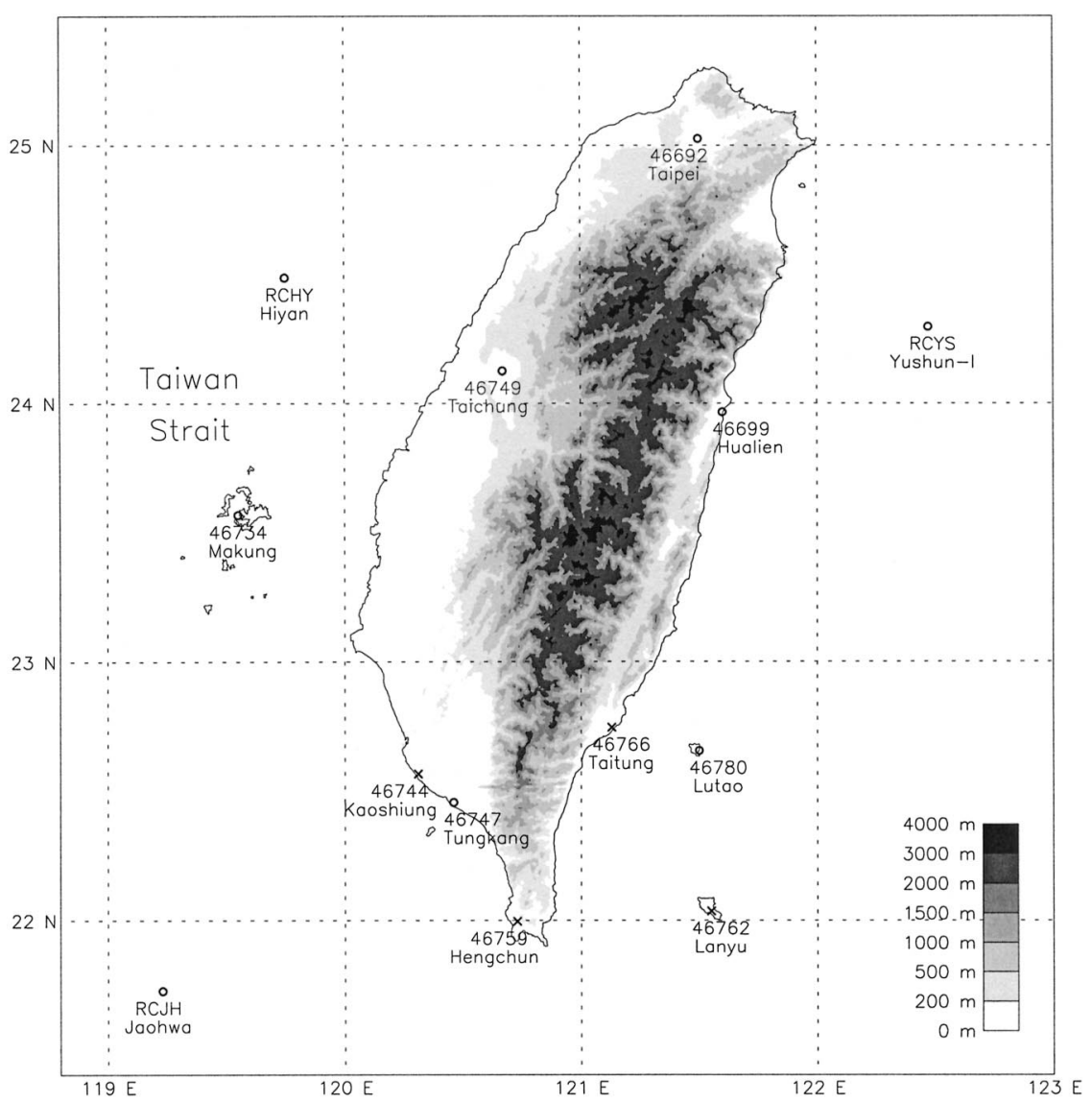

FIG. 1. Terrain of Taiwan and locations of rawinsonde stations (circles) during Taiwan Area Mesoscale Experiment (TAMEX). Surface stations discussed in the text are indicated by cross signs.

sification stage, but increased to above 0.4 during the mature and weakening stages to reach a maximum of 0.535 at 0900 UTC 8 June (Table 1). Then, Fr decreased again (not shown). In a study on a barrier jet along the northwestern coast of Taiwan in TAMEX, Li and Chen

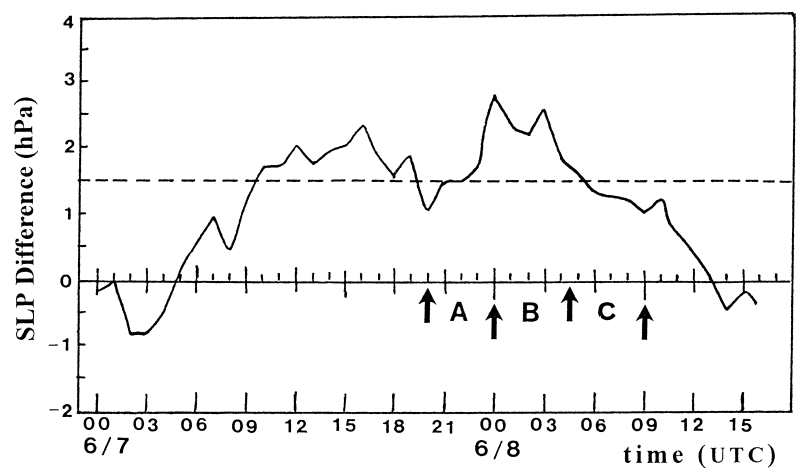

FIG. 2. Time series of sea level pressure (SLP) difference between windward side (Kaoshiung) and lee side (Taitung) of southern CMR in Taiwan, and identified life stages of case. Mean diurnal SLP variation in May-Jun is removed. Letters A, B, and C denote intensification, mature, and weakening stages, respectively.
(1998) used 12-h data, a mountain height of $2.5 \mathrm{~km}$, and estimated the Fr to be slightly over 0.4 on $7-8$ June (their Fig. 8a), consistent with the value obtained here. Similarly, the value of Ro also increased from 1.591 at 2100 UTC 7 June to 3.276 at 0900 UTC 8 June (Table 1). With these values of Fr and Ro, we can expect in the current case the splitting of flow and the presence of a stagnant point at the windward side, and that flow moved both around and over the mountain. In addition, as both Fr and Ro increased, more low-level air would be able to climb over the mountain, as opposed to around the mountain.

\section{Results}

\section{a. Synoptic conditions}

Figure 4 presents the synoptic weather charts at sea level, 850-, 700-, and 500-hPa levels at 0000 UTC 8 June 1987. The mature stage was just under way at this time. The sea level Mei-yu front extended from northeast to southwest and passed through northern Taiwan, with a frontal disturbance over Taiwan Strait (Fig. 4a). Strong cyclonic vorticity along the Mei-yu front was 
TABLE 1. Upstream Froude number (Fr) and Rossby number (Ro) calculated using sounding data below $3000 \mathrm{~m}$ at Jaohwa (RCJH) and a mountain height of $2000 \mathrm{~m}$ and a characteristic width of $70 \mathrm{~km}$.

\begin{tabular}{|c|c|c|c|c|c|}
\hline \multirow{3}{*}{$\begin{array}{c}\text { Life stage } \\
\text { Time / UTC } \\
\text { LST }\end{array}$} & \multirow{3}{*}{$\begin{array}{c}\text { Intensification } \\
2100 \text { UTC } 7 \text { Jun } \\
\text { 0500 UTC } 8 \text { Jun }\end{array}$} & \multicolumn{2}{|c|}{ Mature } & \multicolumn{2}{|c|}{ Weakening } \\
\hline & & 0000 UTC 8 Jun & 0300 UTC 8 Jun & 0600 UTC 8 Jun & 0900 UTC 8 Jun \\
\hline & & 0800 UTC 8 Jun & 1100 UTC 8 Jun & 1400 UTC 8 Jun & 1700 UTC 8 Jun \\
\hline Froude no. & 0.285 & 0.417 & 0.442 & 0.445 & 0.535 \\
\hline Rossby no. & 1.591 & 2.343 & 2.436 & 2.697 & 3.276 \\
\hline
\end{tabular}

indicated by the strong shear across the front to the northeast of Taiwan. At 850 and 700 hPa (Figs. 4b and $4 \mathrm{c})$, the main trough, also with a northeast-southwest orientation, was clear and lagged the surface front. The prevailing wind in the lower troposphere in the Taiwan area was westerly to southwesterly, with a wind speed of roughly $10 \mathrm{~m} \mathrm{~s}^{-1}$, and flow diffluence in southern Taiwan at these levels was quite evident. At $500 \mathrm{hPa}$ (Fig. 4d), the main trough was located further west over mainland China, and the prevailing wind was from the west. The slight veering of wind with height suggested warm air advection over Taiwan.

At 1200 UTC June 8, the surface Mei-yu front had already passed Taiwan and entered the Pacific Ocean (not shown). Over Taiwan, postfrontal northerly winds prevailed near the surface, while westerly winds persisted at 700 and $500 \mathrm{hPa}$. Thus, the backing of winds with height indicated strong cold air advection after frontal passage. Also noticeable was an overall increase in wind speed in the lower troposphere from 0000 to 1200 UTC, particularly evident at $700 \mathrm{hPa}$, where lowlevel jets (LLJs) appeared at both northern and southern Taiwan (not shown).

\section{b. Mesoscale analyses}

Hourly mesoscale analyses of SLP at 1-hPa interval (or $0.5-\mathrm{hPa}$ interval as needed) and surface streamline from 1800 UTC 7 June to 0900 UTC 8 June 1987 are displayed in Fig. 5. Description and discussion for the three stages and for the precipitation are presented as follows.

\section{1) IntensificAtion Stage (2000 UTC 7 June- 0000 UTC 8 JUNE)}

At 1800 UTC 7 June (Fig. 5a), 2 h before the intensification stage, a mesolow with closed isobar had already formed to the southeast of Taiwan with its center just north of Lutao near $22.9^{\circ} \mathrm{N}, 121.5^{\circ} \mathrm{E}$. Note that the analyses were limited to regions west of $122^{\circ} \mathrm{E}$ due to a lack of data farther east. An east-west mesoscale highlow couplet existed in southern Taiwan, with high pressure on the windward side and low pressure on the lee side of the southern CMR and a SLP difference of about $4.5 \mathrm{hPa}$. This high-low couplet pattern was consistent with the value of Ro (Table 1), and would exist throughout the entire life period of the mesolow. The surface streamline analysis showed that prevailing southwesterly airflow split upstream of the CMR, offshore of southwestern Taiwan, with one branch to the north and the other around the southern end of the terrain to the east. Thus, the mesoscale patterns of SLP and streamlines were very similar to those discussed by $\mathrm{Li}$ and Chen (1998). During this stage the wind speed at Lanyu Island was about $10-15 \mathrm{~m} \mathrm{~s}^{-1}$, considerably stronger than those observed upstream of CMR at Makung and ship Jaohwa (Fig. 5a).

Between 1900 and 2300 UTC (Figs. 5b and 5c), similar patterns of SLP and streamlines persisted through the intensification stage, except that the Mei-yu front gradually approached northern Taiwan. The central pressure of the mesolow dropped slowly from above to below $1002 \mathrm{hPa}$ near the end of intensification stage at 2300 UTC (Fig. 5c). As the airflow split upstream, a deformation field formed with a stagnant point at its center, and an offshore wind prevailed along the southwestern coast of Taiwan, corresponding to a return flow. During this period, surface wind with cyclonic curvature but no closed circulation flowed through the center of the mesolow and its adjacent area. The streamline analysis, although somewhat subjective, also indicated the formation of a mesovortex (center marked as C) at 2100 UTC 7 June at $22.4^{\circ} \mathrm{N}, 120.9^{\circ} \mathrm{E}$ along the southeastern coast (Fig. 5b), just at the northern end of Hengchun Peninsula at the southern tip of Taiwan. This mesovortex was about $90 \mathrm{~km}$ to the southwest of the mesolow center and remained stationary.

\section{2) Mature stage (0000-0430 UTC 8 June)}

At the beginning of mature stage at 0000 UTC 8 June (Fig. 5d), the surface Mei-yu front started to pass through northern Taiwan, and was broken into two segments due to the blocking of high terrain (cf. Fig. 1). A frontal low was analyzed over the northern Taiwan Strait (offshore of northwestern Taiwan) based on additional data from research vessel Hiyan (RCHY) and on the time continuity in mesoscale analyses, but its location was somewhat to the north as compared to that analyzed in the synoptic chart in Fig. 4a. While the mesovortex $\mathrm{C}$ formed earlier over Hengchun Peninsula remained stationary, a second vortex appeared near the mesolow center at 0000 UTC but disappeared immediately afterward, thus producing a mesocyclone only briefly. This second vortex was analyzed as wind im- 


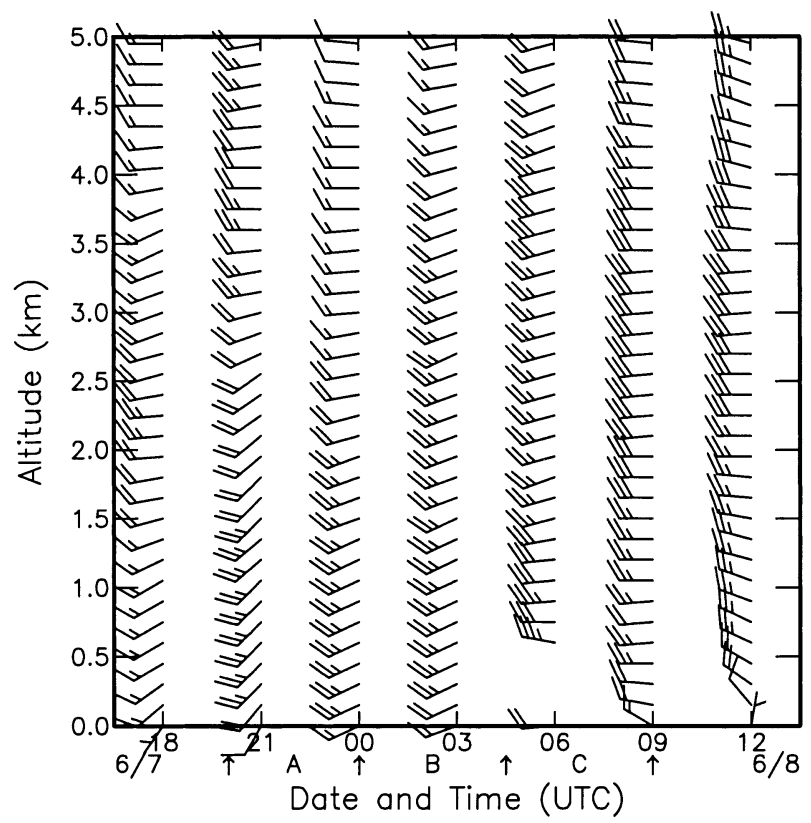

FIG. 3. Vertical profiles of horizontal wind below $5 \mathrm{~km}$ at Jaohwa (RCJH) from 1800 UTC 7 Jun to 1200 UTC 8 Jun 1987 at 3-h intervals (conventional plots, with one full barb indicating $5 \mathrm{~m} \mathrm{~s}^{-1}$ ). Life stages of the mesolow A, B, and C are indicated.

mediately to the north that shifted from offshore to onshore, and therefore its formation was likely related to the interaction between prevailing wind and local circulation such as land-sea breeze and/or mountain-valley breeze along the coastal area.

During the remaining hours of the mature stage from 0100 to 0400 UTC 8 June (Figs. 5e and 5f), the surface Mei-yu front continued to pass through northern Taiwan, and the segment east of the CMR moved faster than the one west of the CMR. The wind speed in southern Taiwan Strait as observed at ship Jaohwa increased from $5 \mathrm{~m} \mathrm{~s}^{-1}$ during intensification stage to around $10 \mathrm{~m} \mathrm{~s}^{-1}$, and wind speed at Lanyu also strengthened considerably to $15-20 \mathrm{~m} \mathrm{~s}^{-1}$. This signified the formation of a localized LLJ on the lee side by terrain blocking. During the mature stage, the center of the mesolow moved westward and became closer to the coast, while the Kaoshiung minus Taitung SLP reached a maximum of about 2.5 to $3 \mathrm{hPa}$ (also Fig. 2), but the central SLP of the mesolow increased slightly to near $1003 \mathrm{hPa}$. The mesolow to the southeast of Taiwan possessed only cyclonic flows without a closed circulation throughout the mature stage, except at 0000 UTC (Fig. 5d). The Hengchun Peninsula mesovortex moved northward slowly along the southeast coast of Taiwan from 0100 UTC (Fig. 5e) to about $22.7^{\circ} \mathrm{N}, 121^{\circ} \mathrm{E}$ at 0400 UTC (Fig. 5f). During this period, offshore flow in the southwestern plain was still evident. Note that the cyclonic vorticity along the front to the east of Taiwan as seen in Fig. 4a was also clearly indicated by surface winds along the east coast of Taiwan in Figs. 5e and 5f.

\section{3) Weakening stage (0430-0900 UTC 8 June)}

At the beginning of the weakening stage at 0500 UTC 8 June (Fig. $5 \mathrm{~g}$ ), the eastern segment of the Mei-yu front moved southward into the mesolow region and provided cyclonic vorticity. The mesolow then moved slightly northward, merged into the front, and transformed into a migratory frontal mesocyclone, moving eastward gradually along the front through the weakening stage (Figs. 5h-j). Although a mesocyclone can also form due to terrain modification of frontal circulation, the interaction between the Mei-yu front and the mesolow likely played a major role in the transformation process here since the low was preexisting to provide the disturbance. Near the southeast coast of Taiwan, the Hengchun Peninsula mesovortex C lasted through 0600 UTC (Fig. 5h) until the frontal passage, and the front passed through Lutao near 0800 UTC (Fig. 5i). The western segment of the Mei-yu front moved southward at a slower speed initially, and passed through Makung around 0500 UTC (Fig. 5g). However, it moved significantly faster afterward, and the two segments reconnected with each other at 0900 UTC (Fig. 5j), reforming a continuous surface Mei-yu front at the end of the weakening stage. The offshore wind in the southwestern plain was still visible until the frontal passage near 0800 UTC (Fig. 5i).

\section{4) Precipitation}

The distribution of accumulated rainfall amounts $(\mathrm{mm})$ in southern Taiwan in the three stages, normalized to daily total to facilitate precipitation intensity comparison, was analyzed in Fig. 6. Precipitation occurred in all three stages, and tended to be heavier in a region along the southwestern coast $\left(>100 \mathrm{~mm} \mathrm{day}^{-1}\right)$ during the intensification stage. As the prevailing wind strengthened in the mature stage, heavy rain fell along the coast $\left(>180 \mathrm{~mm} \mathrm{day}^{-1}\right)$ as well as at the windward side of the southern CMR, just west of the ridge $(>120$ mm day ${ }^{-1}$, Fig. 6b). In the weakening stage (Fig. 6c), while local rainfall maxima still appeared along the windward side of the CMR, precipitation was more evenly distributed over the southwestern plain, suggesting that the rainfall was at least partially related to the frontal passage. At the lee side, no precipitation was observed until the weakening stage, when the rainfall along the southeastern coast was mainly due to the passage of the Mei-yu front.

\section{c. Time-height cross sections}

For the time-height cross-section analysis, stations Makung (46734), Tungkang (46747), and Lutao (46780) were used to represent the atmospheric evolution over Taiwan Strait, on the windward and lee sides, respectively. Meteorological variables and parameters shown include wind and pressure anomaly (Fig. 7), temperature anomaly and relative humidity (Fig. 8), and potential 


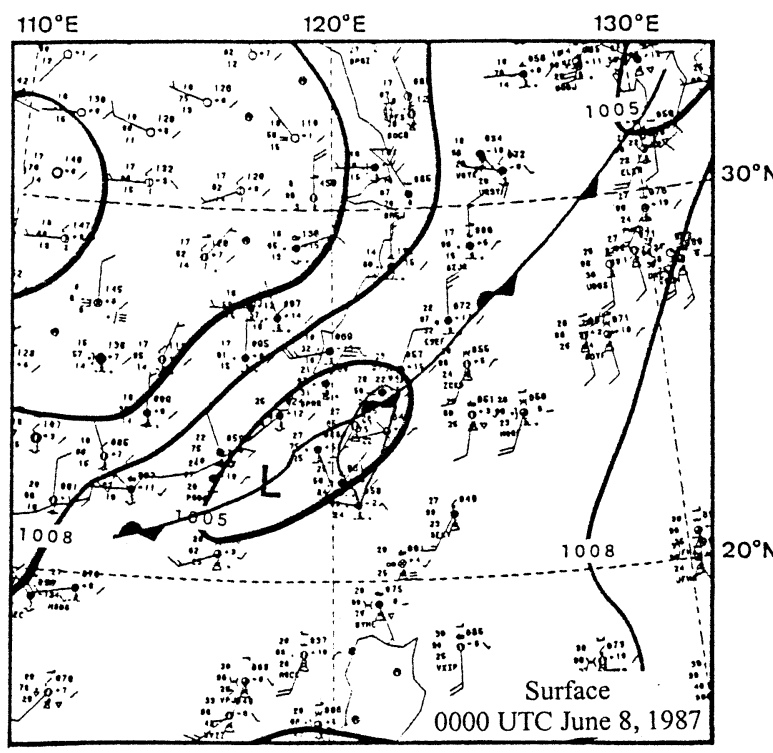

(a)

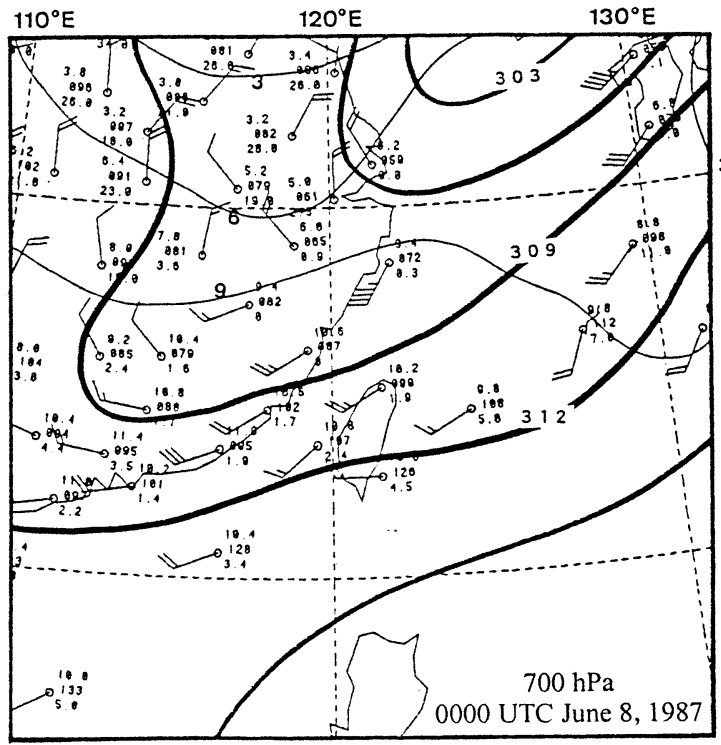

(c)

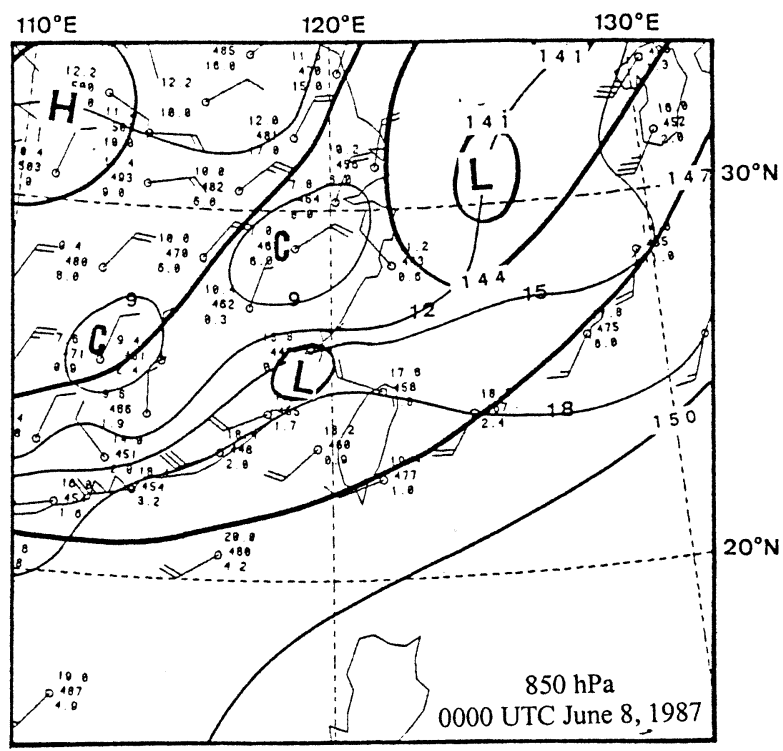

(b)

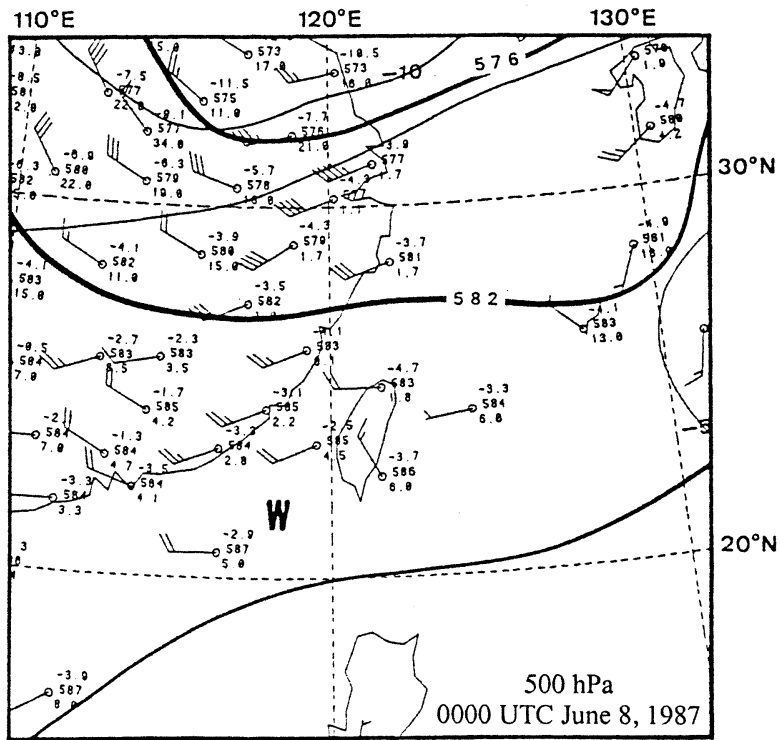

(d)

FIG. 4. Synoptic weather maps at (a) surface, (b) $850 \mathrm{hPa}$, (c) $700 \mathrm{hPa}$, and (d) $500 \mathrm{hPa}$ for 0000 UTC 8 Jun 1987. Thick solid lines are pressure $(\mathrm{hPa})$ at surface and geopotential height (dam) at other levels. Thin lines are isotherms $\left({ }^{\circ} \mathrm{C}\right)$, and station plots follow meteorological convention.

temperature $(\theta)$ and equivalent potential temperature $\left(\theta_{e}\right.$; Fig. 9). In order to better visualize pressure and temperature features on the windward and leeward sides of Taiwan, deviations from a mean state were illustrated. Rawinsonde data at research vessel Jaohwa (RCJH), which was located upstream from Taiwan (Fig. 1), were used to represent the least disturbed environmental mean states under southwesterly flow. Thus, anomalies in Figs. 7 and 8 were calculated by subtracting values at the same time/height at Jaohwa from the original values at the site under consideration. One additional advantage of using time-varying data at Jaohwa as the environmental mean states is that the procedure also removes most of the diurnal fluctuations in pressure and temperature from the anomaly fields.

\section{1) Wind AND PRESSURE ANOMALY}

The time-height cross-section of wind at Makung (Fig. 7a) showed a strengthening in southwesterly wind 

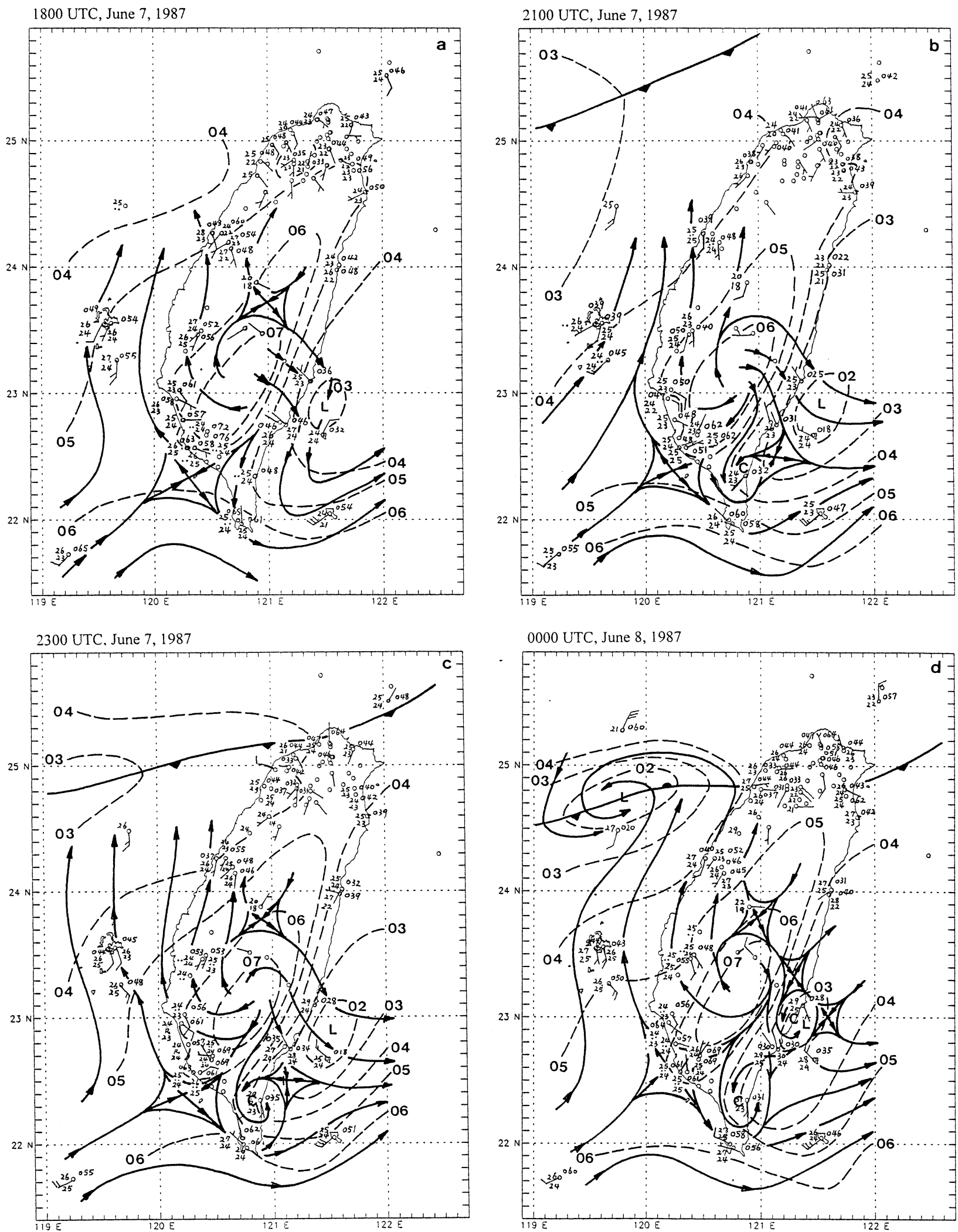

FIG. 5. Hourly surface mesoscale analyses of sea level pressure (dash lines, at 1-hPa intervals) and streamlines (solid lines with arrows) from (a) 1800 UTC 7 Jun to (j) 0900 UTC 8 Jun 1987. Surface fronts are also analyzed. 

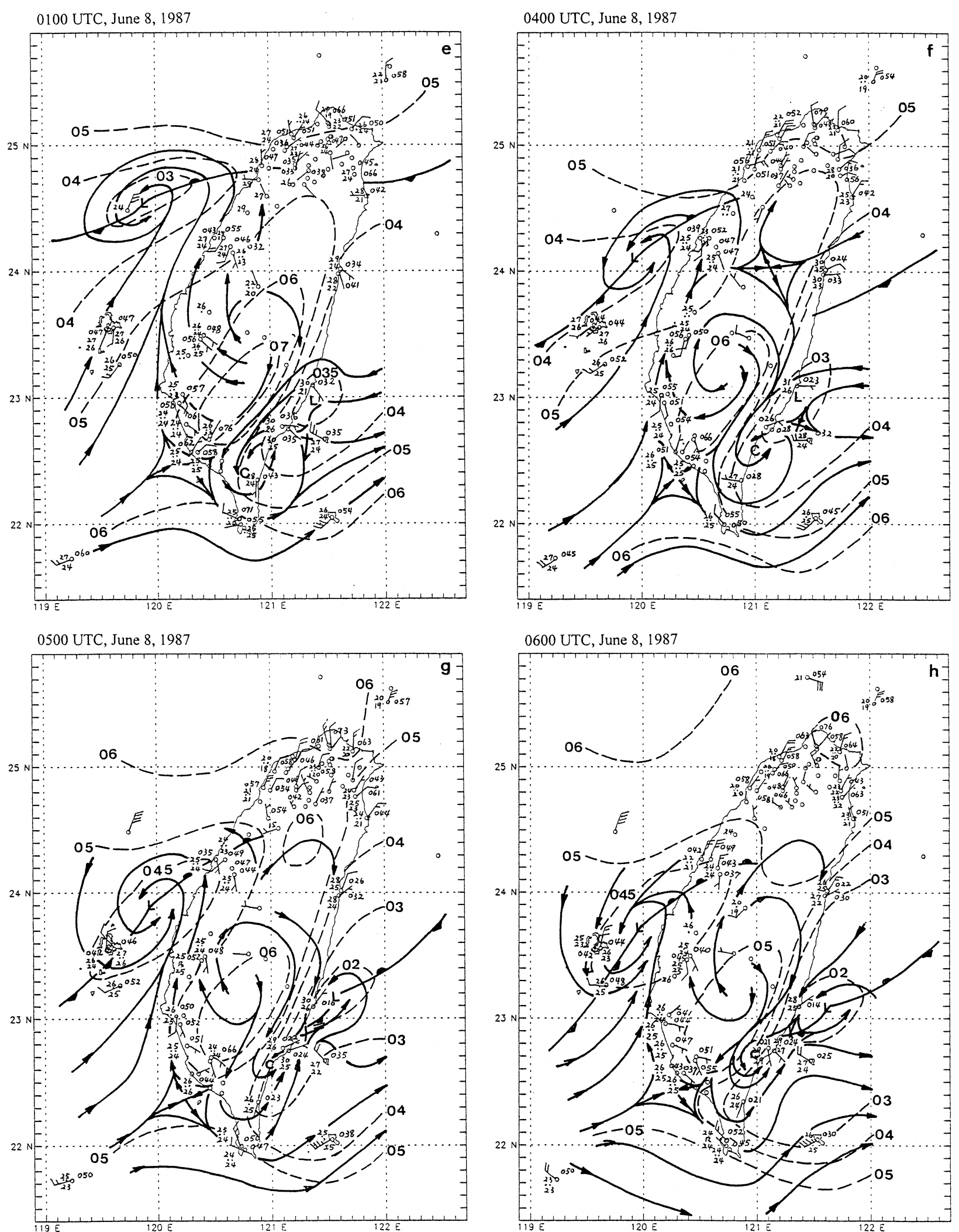

FIG. 5. (Continued) 

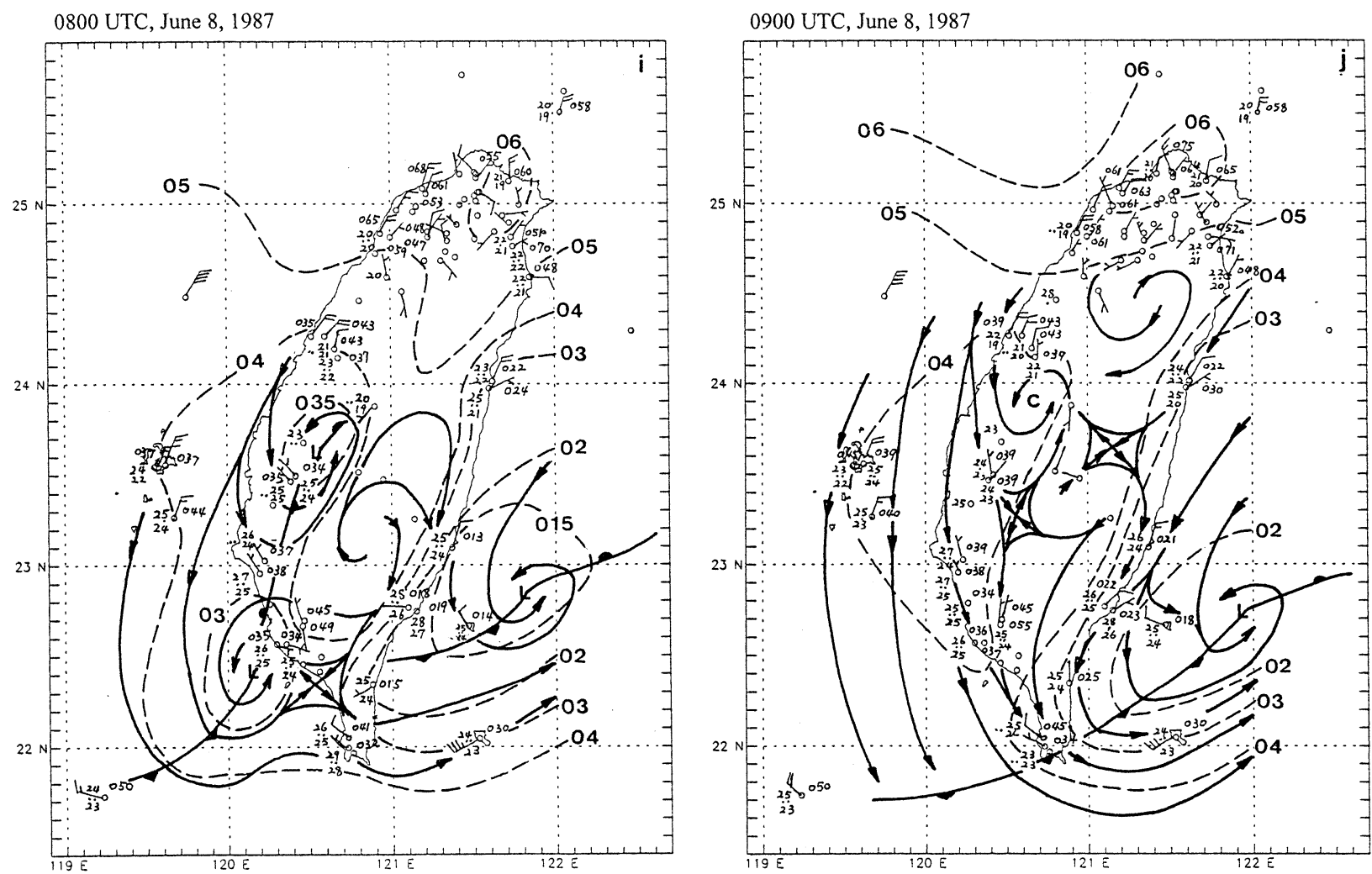

FIG. 5. (Continued)

speed in the lower troposphere from about $7.5-10 \mathrm{~m}$ $\mathrm{s}^{-1}$ to $15-20 \mathrm{~m} \mathrm{~s}^{-1}$, with directions turning more perpendicular to the terrain with time, similar to the wind profiles at Jaohwa (Fig. 3). The surface front passed Makung around 0500 UTC 8 June, and the cold air indicated by the northeasterly winds behind the front was about $1.5-\mathrm{km}$ thick. The passage of a middle-tropospheric trough between 0900 and 1200 UTC was also evident, as the wind direction changed from southwest to west-northwest, consistent with the synoptic analysis (Fig. 4).

At Tungkang, where sounding was available only every $6 \mathrm{~h}$, westerly wind also prevailed and enhanced throughout the stages from about 7.5 to $10-15 \mathrm{~m} \mathrm{~s}^{-1}$, with a region of strong wind extending downward gradually (Fig. 7b). Near the surface, the wind was from the north or northeast, consistent with the offshore flow seen in Fig. 5. The passage of the middle-tropospheric trough, compared to Makung, was less clear. At Lutao, the southwest-west wind was considerably weaker than at the other sites $\left(<10 \mathrm{~m} \mathrm{~s}^{-1}\right)$, except near the surface during intensification and mature stages (Fig. 7c). The Mei-yu front passed Lutao at around 0800 UTC, and the northeast flow had a thickness of about $1 \mathrm{~km}$ at 1200 UTC.

The pressure anomaly at Makung was relatively small. Most anomaly centers in the lowest $5 \mathrm{~km}$ were within $1.0 \mathrm{hPa}$ from Jaohwa, as this site is farther from the CMR (Fig. 7d). The positive and negative anomalies above $1 \mathrm{~km}$ at 0600 and after 0900 UTC 8 June were likely linked to a more evident passage of the trough. At Tungkang, negative pressure anomaly centers of about $-2.0 \mathrm{hPa}$ appeared above $2 \mathrm{~km}$ by 0300 UTC 8 June, and afterward a moderate but clear increase in pressure existed at all levels, especially below $1 \mathrm{~km}$ (Fig. $7 \mathrm{e}$ ), in agreement with the establishment of the windward side high. A maximum of nearly $1.0 \mathrm{hPa}$ was reached at the surface between 0600 and 0900 UTC (in weakening stage). At Lutao, on the other hand, the decreasing trend from 0000 to 0600 UTC 8 June was much stronger and consistent at all levels below $5 \mathrm{~km}$ (Fig. $7 \mathrm{f}$ ). The negative pressure anomaly reached a minimum of $-5.1 \mathrm{hPa}$ near the surface at $0600 \mathrm{UTC}$, and weakened between 0600 and 0900 UTC.

\section{2) Temperature ANOMAly AND Relative HUMIDITY}

The temperature anomaly below $500 \mathrm{~m}$ was negative at Makung, and perhaps was mostly due to the latitudinal difference from Jaohwa (Fig. 8a). Above 500 m, temperature anomalies were mostly positive, and many anomaly centers (on order between $1^{\circ}-2^{\circ} \mathrm{C}$ ) were consistent with stronger southerly wind components (cf. Fig. 7a) over the Taiwan Strait. The negative anomaly below $3.5 \mathrm{~km}$ after 0600 UTC (with a minimum of 

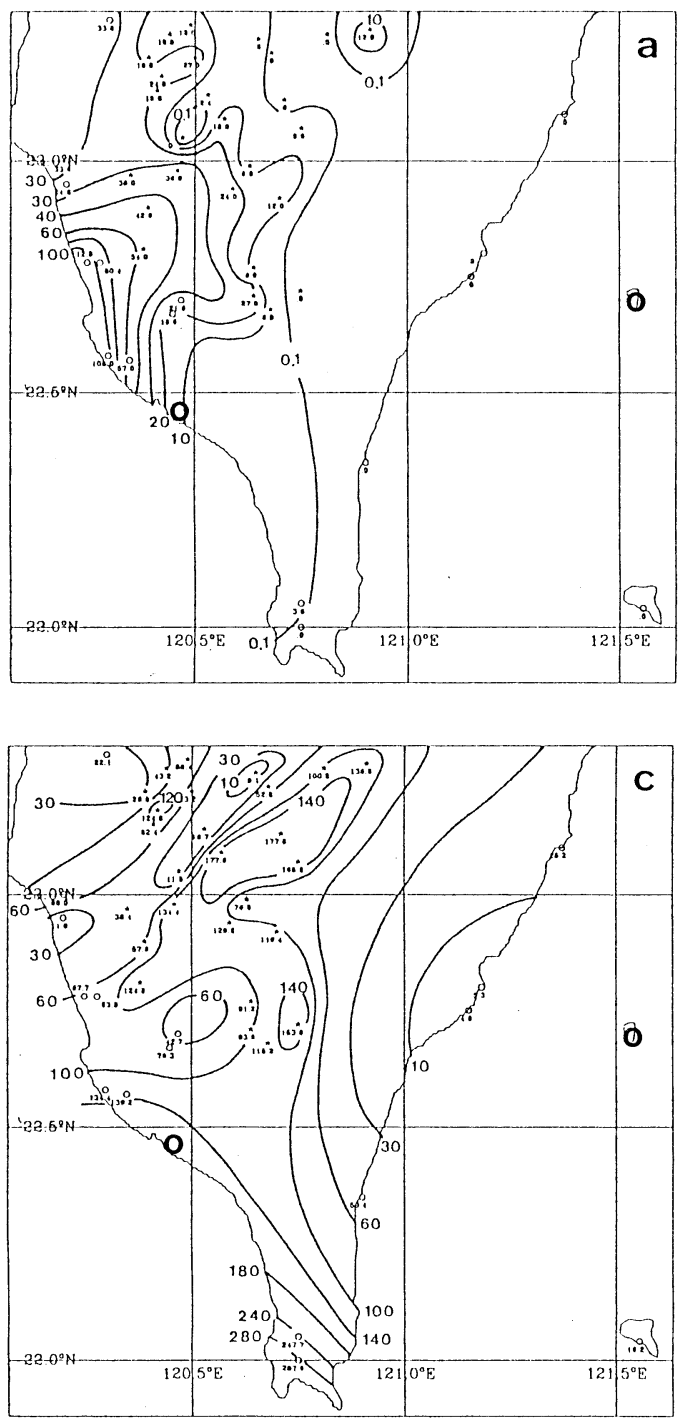

below $-3^{\circ} \mathrm{C}$ ) was concurrent with the cold air advection behind the Mei-yu front, and occurred also in phase with the pressure anomaly linked to trough passage.

Figure $8 \mathrm{~b}$ shows that negative temperature anomaly existed below $3.5 \mathrm{~km}$ throughout most of the stages at Tungkang, and was strongest from 0000 to 0300 UTC during the mature stage. Three centers appeared at about $100 \mathrm{~m}$ (over $\left.-3^{\circ} \mathrm{C}\right), 1 \mathrm{~km}\left(-2.3^{\circ} \mathrm{C}\right)$, and $3 \mathrm{~km}\left(-1.9^{\circ} \mathrm{C}\right)$. The higher ones were most likely caused by adiabatic cooling as air parcels rose at the windward side of southern CMR, while those at lower levels are likely, at least in part, to be the result of evaporative cooling, both supported by the precipitation distribution (Fig. 6). The positive temperature anomaly below $2.5 \mathrm{~km}$ near the end at 1200 UTC was likely a result of a stronger shading effect from northeasterly winds by the CMR compared to Jaohwa. At Lutao (Fig. 8c), temperature anomaly was positive almost everywhere in the cross section, in contrast to the negative values at Tungkang. The most

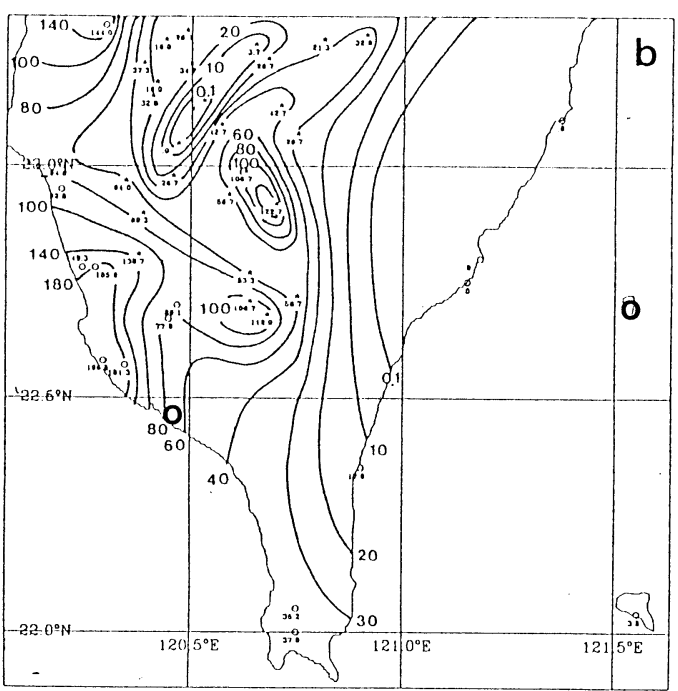

FIG. 6. Distribution of normalized rainfall amount $\left(\mathrm{mm} \mathrm{day}^{-1}\right)$ during (a) intensification, (b) mature, and (c) weakening stages. Tungkang and Lutao are marked as open circles.

significant feature was the maximum center of $4.7^{\circ} \mathrm{C}$ near $1.2 \mathrm{~km}$ at 0600 UTC, clearly caused by the subsidence warming on the lee side of the CMR. From 0300 to 0900 UTC, the temperature anomaly field at Lutao above and below $1 \mathrm{~km}$ also had different characteristics, and will be further discussed shortly.

Figure $8 \mathrm{~d}$ shows that at Makung the relative humidity decreased below $1.5 \mathrm{~km}$ during the intensification and mature stages and increased afterwards, with a minimum of $75 \%$ near $500 \mathrm{~m}$ at 0300 UTC. Relative humidity at Tungkang (Fig. 8e) remained high everywhere in the cross section $(>89 \%)$ with only small variation in values, consistent with the precipitation. A relative dry center of $89 \%$ appeared near $2.5 \mathrm{~km}$ at 0000 UTC 8 June, while another center of $92 \%$ existed near 500 $\mathrm{m}$ at 0600 UTC. In Lutao (Fig. 8f), a clear and steady drying tendency was observed between 1 and $2 \mathrm{~km}$ from 1800 UTC 7 June to shortly after 0600 UTC 8 June. Clearly caused by the subsidence warming at the leeside 

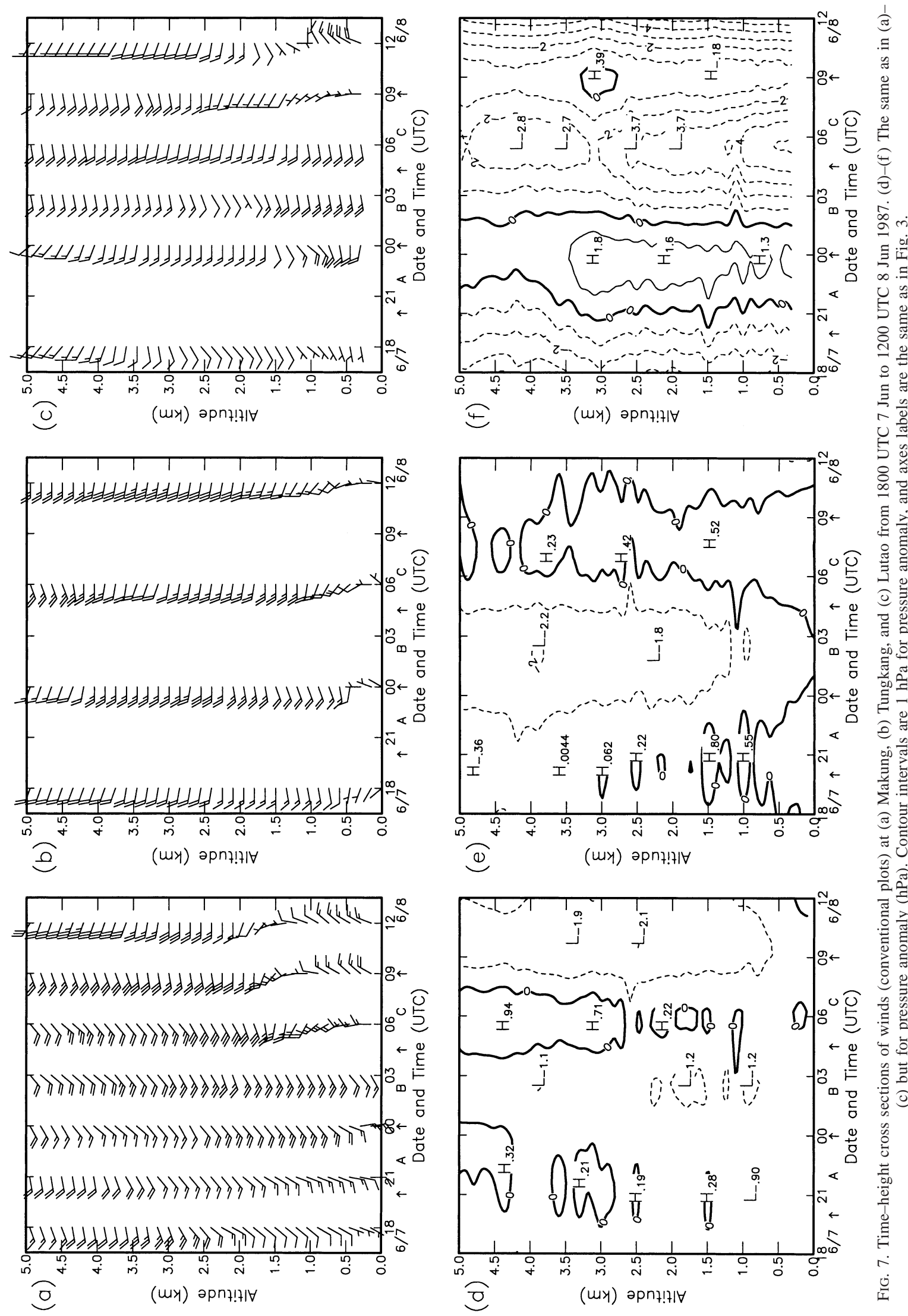

U

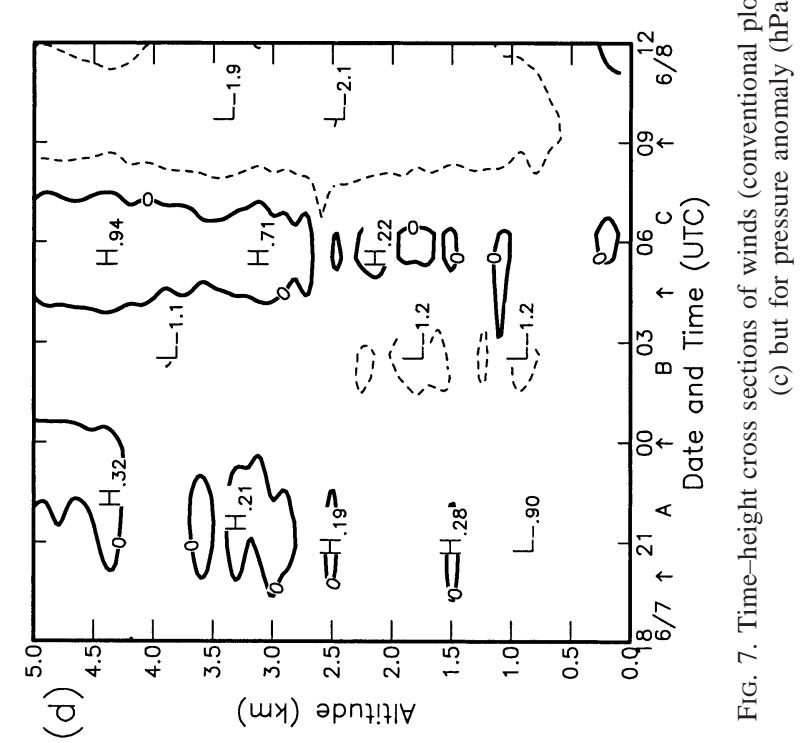



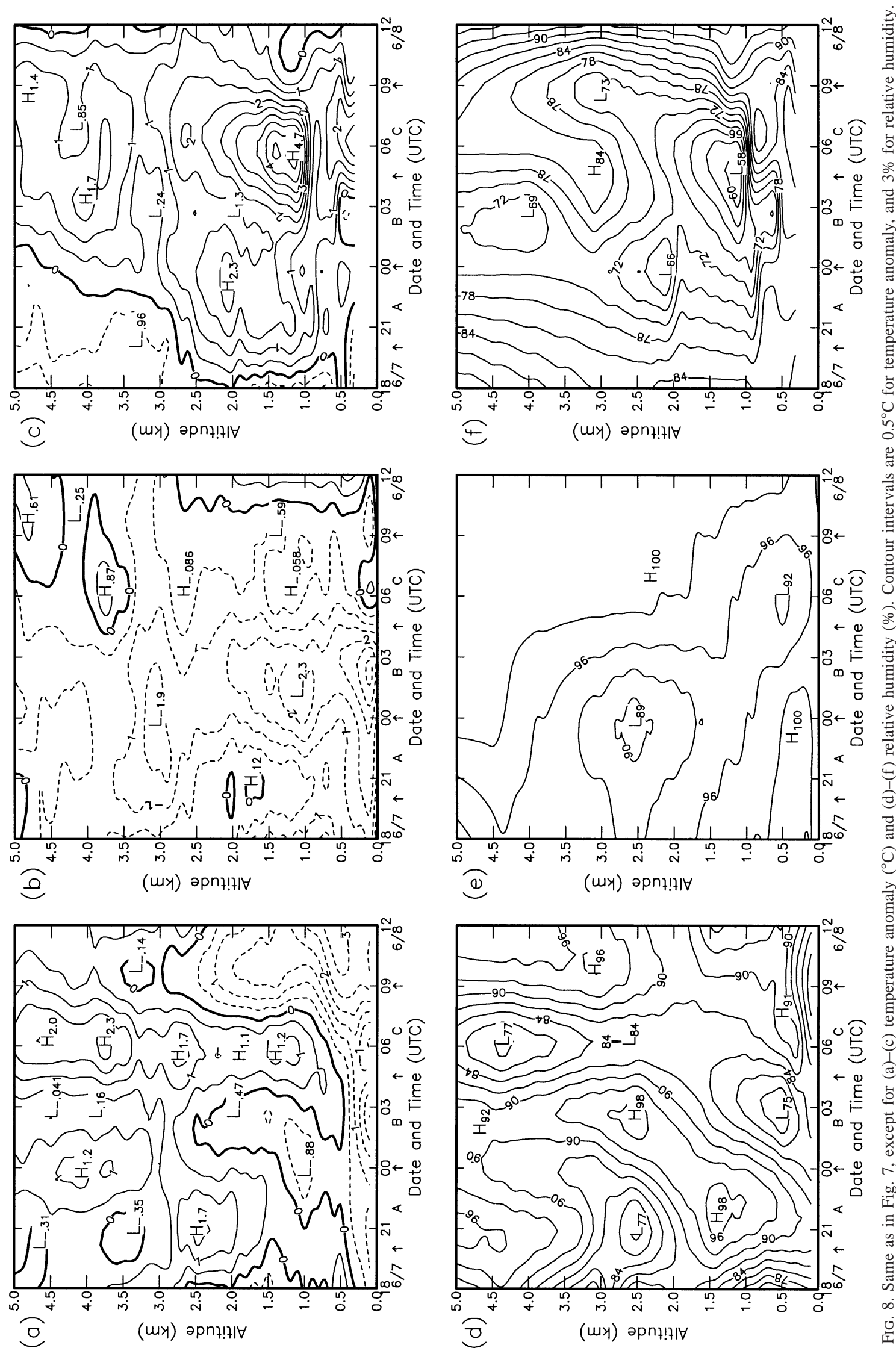

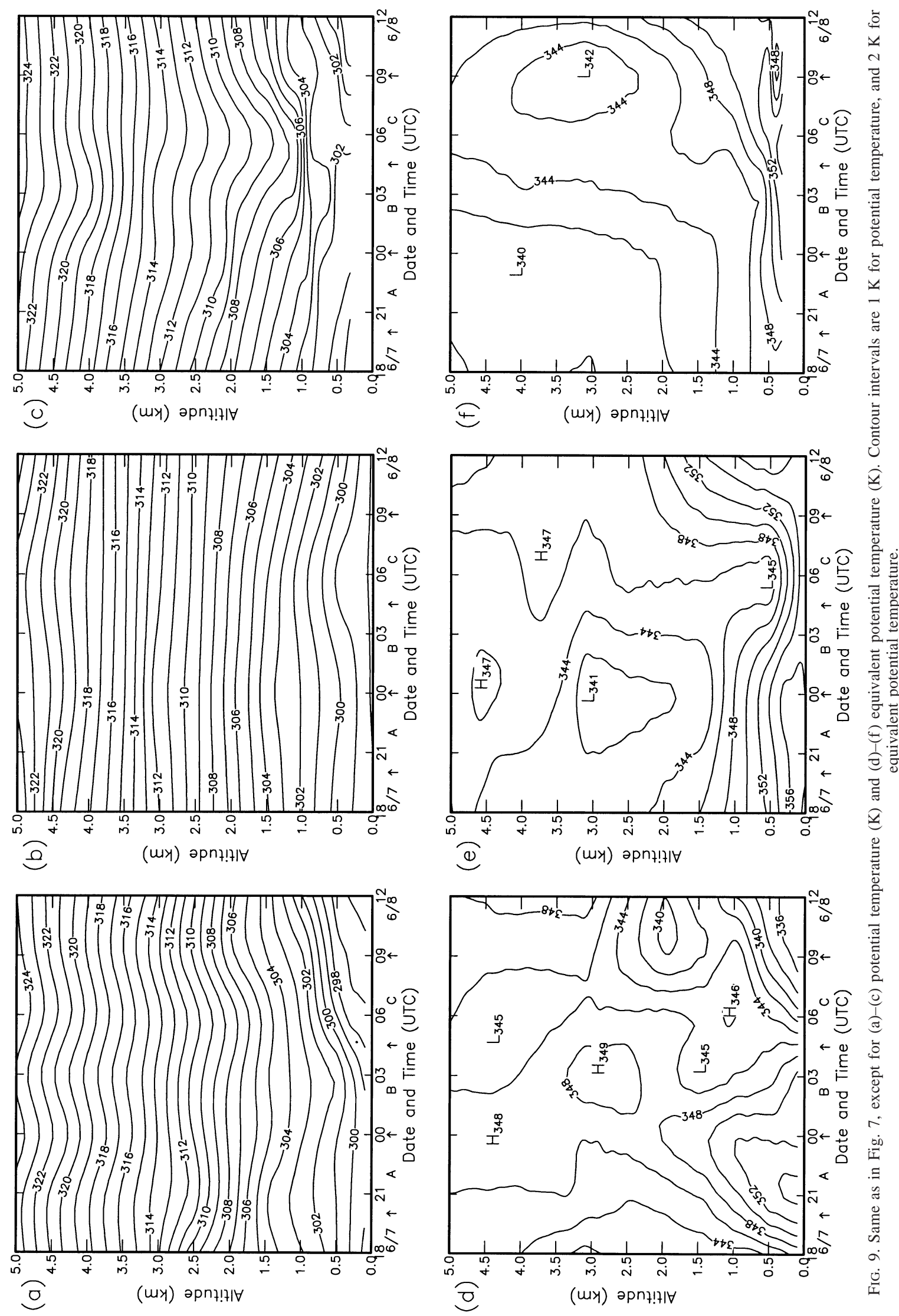
of the CMR, a dry center of 58\% was reached near 1.2 $\mathrm{km}$.

\section{3) Potential temperature And equivalent POTENTIAL TEMPERATURE}

At Makung, potential temperature $(\theta)$ below $1.5 \mathrm{~km}$ indicated warming ( $\theta$ lines sloping down to the right) before about 0300 UTC 8 June, in agreement with the decline in relative humidity (Fig. 9a). The warming above $1.5 \mathrm{~km}$ by 0600 UTC and cooling ( $\theta$ lines sloping up) toward the later stages below $2 \mathrm{~km}$ were also consistent with temperature anomaly (cf. Fig. 8a). At Tungkang, $\theta$ cross section showed cooling below about 1.2 $\mathrm{km}$ from 0000 to 0600 UTC 8 June and warming afterward (Fig. 9b). Above $1.2 \mathrm{~km}, \theta$ lines remained relatively flat through the stages, but a slight warming trend at $1.2-2.5 \mathrm{~km}$ starting from 0000 UTC is still visible. This warming could be caused by latent heat release associated with uplifting, and was in agreement with the high and rising relative humidity over the same region in Fig. 8e.

At Lutao, consistent with the subsidence warming, $\theta$ lines between 1 and $2 \mathrm{~km}$ sloped downward significantly before 0600 UTC 8 June (in weakening stage), then upward afterward in response to the frontal passage (Fig. 9c). The little spatial separation between $\theta$ lines in the vertical near $1 \mathrm{~km}$ in late mature and early weakening stages (from about 0200 to 0700 UTC 8 June) indicated a highly stable layer and the bottom of sinking motion at the lee side of the CMR. The increase in potential temperature from 1800 UTC 7 June to 0600 UTC 8 June at Lutao was strongest between 1.5 and 2 $\mathrm{km}$, where the total increase was roughtly $5 \mathrm{~K}$. Below $1 \mathrm{~km}$, the vertical $\theta$ gradient was small near 0600 UTC [1400 local standard time (LST)] 8 June, indicating that the air was well mixed vertically inside the planetary boundary layer, which was capped by the strong subsidence (Fig. 9c). Therefore, the temperature anomaly field at Lutao also showed different characteristics above and below about $1 \mathrm{~km}$ near this time (Fig. 8c).

The cross section of equivalent potential temperature $\left(\theta_{e}\right)$ at Makung indicates a potentially unstable layer $2.5-\mathrm{km}$ thick in the intensification stage, which grew to $3.5 \mathrm{~km}$ in early mature stage (Fig. 9d). The lowest levels during late mature and weakening stages were nearly potentially neutral, while the stability in the lower troposphere increased considerably after the frontal passage. At Tungkang, the potentially unstable layer remained at roughly $2.5-3-\mathrm{km}$ thick throughout the stages (Fig. 9e). Another region of potential neutrality extended upward from about 1 to $3 \mathrm{~km}$ in the mature stage, and was likely related to the rising motion discussed earlier. At Lutao (Fig. 9f), a slightly potentially unstable and neutral layer remained more than $2-\mathrm{km}$ thick throughout the stages.

\section{d. Low-level flow}

Some features seen in surface mesoscale analyses (Fig. 5) near the deformation field at the windward side of the southern CMR - including airflow splitting, stagnant point, and return flow-are formed when the airflow is blocked by the terrain at low-Fr regime. To investigate further the depth of these phenomena, streamlines were also analyzed at 200, 400, and $600 \mathrm{~m}$ above ground using rawinsonde and pilot balloon data available in the mature stage on the western plain of Taiwan. Results, shown in Fig. 10, were for 0000 and 0300 UTC 8 June. At 0000 UTC, evident diffluence near the southwestern coast of Taiwan existed to a height of at least $600 \mathrm{~m}$ above ground, with flow splitting, return flow, and stagnant point at windward side present at least to $400 \mathrm{~m}$ (Figs. 10a-c). Thus, the blocking effect of terrain was clear at these levels. The formation of a localized barrier jet to the northwest of Taiwan was indicated by the strongest southerly wind at Taichung station at 400 and $600 \mathrm{~m}$ (also Li and Chen 1998). At 0300 UTC, flow splitting with stagnation could only be seen at $200 \mathrm{~m}$, but the diffluence was still clear at all three elevations (Figs. 10d-f). The presence and lowering of the layer with stagnation from 0000 to 0300 UTC were consistent with both the Fr values themselves and the increase in Fr with time. The apparent reduction in flow deflection and splitting upstream of CMR was also in agreement with the increase in Ro. Nevertheless, during the life stages of the present case, significant blocking existed at least to $600 \mathrm{~m}$ and air parcels below this elevation tended to split and move around the terrain when encountering the CMR.

\section{e. Case summary}

The present case of mesolow during TAMEX on 8 June 1987 developed on the lee side of the CMR when prevailing west-southwesterly winds strengthened and Fr increased as the Mei-yu front approached Taiwan from the north. The flow at lower levels, being blocked by the terrain, split upstream and moved around it, producing LLJs in both northwestern Taiwan and the southern end of the CMR, similar to the condition during IOP-2 (Sun and Chern 1993). Flow above the splitting layer, on the other hand, rose and cooled at the windward side, and sank and warmed on the lee side of the CMR, causing a pair of high-low pressure couplets at sea level. Precipitation from the forced uplifting was observed at the windward (west) side of the mountain range, especially during the mature stage. On the lee side, adiabatic warming was evident between 1 and $2 \mathrm{~km}$ and led to the formation of a stable layer near $1 \mathrm{~km}$.

The mesolow formed before the intensification stage, with closed isobars but not a closed circulation except for a brief 1-h period. The low remained quasi-stationary until the Mei-yu front approached along the eastern coast of Taiwan to provide cyclonic vorticity, and then 

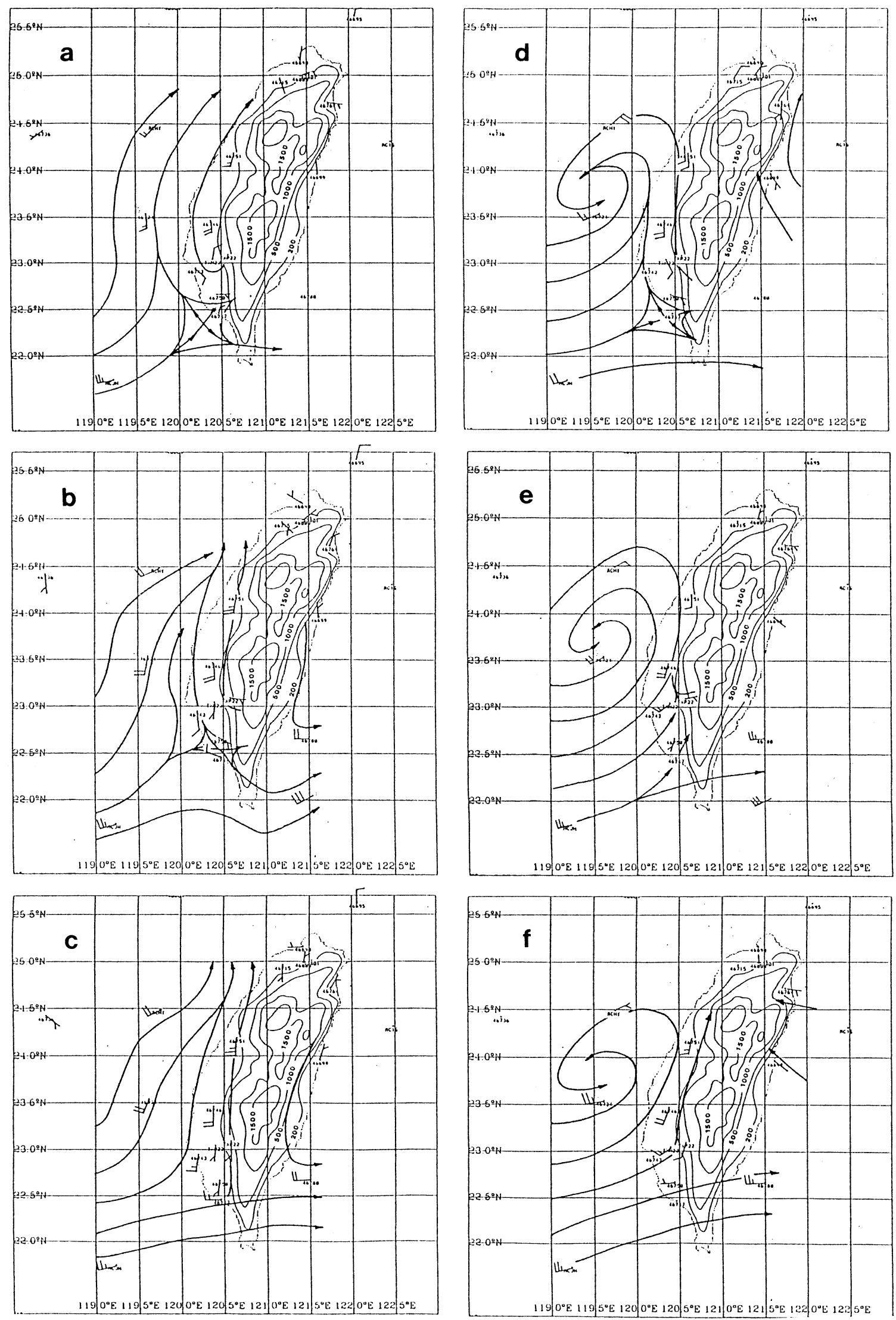
TABLE 2. Estimated 850 -hPa vertical velocity $\left(\omega\right.$ in $\left.\mathrm{Pa} \mathrm{s}^{-1}\right)$ and various terms at 0000 UTC 8 June using the thermodynamic method. All terms are for $850-\mathrm{hPa}$ level, except for $\omega_{\max }$, the maximum $\omega$ as computed from $(\partial T / \partial t) / \sigma$ using Eq. (1).

\begin{tabular}{lcc}
\hline \hline \multicolumn{1}{c}{ Parameter } & Tungkang & Lutao \\
\hline$\sigma\left(10^{-4} \mathrm{~K} \mathrm{~Pa}^{-1}\right)$ & 5.307 & 3.727 \\
$-V_{s}(\partial T / \partial s)\left(10^{-5} \mathrm{~K} \mathrm{~s}^{-1}\right)$ & 1.500 & 0.750 \\
$\omega$ from advection & -0.028 & -0.020 \\
$\omega$ from tendency & 0.079 & 0.248 \\
$\omega_{\max }$ from tendency (height) & $-0.096(650 \mathrm{~m})$ & $0.298(1800 \mathrm{~m})$ \\
Estmated $\omega$ & 0.051 & 0.228 \\
\hline
\end{tabular}

transformed into a migratory mesocyclone along the front. In the intensification and mature stages, a localized mesovortex formed to the southwest of the mesolow, in a region of strong shear vorticity associated with the southern branch of the LLJ. The mesovortex and mesolow were roughly $90 \mathrm{~km}$ apart, and little adjustment in location toward one another was observed. The lack of a geostrophic relationship between the mesolow and the mesovortex was consistent with the large Ro, between 1.6 and 3.3.

\section{Discussion}

\section{a. Vertical motion and mesolow formation}

Using sounding data, the vertical velocity $(\omega)$ can be estimated using the thermodynamic method in a natural and pressure coordinate system as

$$
\omega \approx\left(\frac{\partial T}{\partial t}+V_{s} \frac{\partial T}{\partial s}\right) /\left(\frac{\alpha}{C_{p}}-\frac{\partial T}{\partial p}\right),
$$

where $\partial T / \partial t$ is the temperature tendency, $V_{s}(\partial T / \partial s)$ is the (negative) horizontal temperature advection, $\alpha$ the specific volume, and $C_{p}$ the specific heat at constant pressure. The term $\left(\alpha / C_{p}\right)-(\partial T / \partial p)$ in the denominator is often referred to as the stability factor $(\sigma)$. Since Eq. (1) assumes adiabatic motion, any violation of the assumption will introduce errors in estimated vertical velocity, and in serious conditions even the sign could be incorrect. The method was applied at $850 \mathrm{hPa}$, near the level of strongest subsidence on the lee side, for 0000 UTC 8 June (in the mature stage) so that $-V_{s}(\partial T / \partial s)$ can be estimated using sounding winds and horizontal temperature gradient near the station of interest on the weather map (Fig. 4b). Results at Tungkang (windward side) and Lutao (lee side) are presented in Table 2, which also includes the maximum $\omega$ below $3 \mathrm{~km}\left(\omega_{\max }\right)$ computed from local tendency term alone for comparison.

At Tungkang, $\omega$ was estimated to be $0.051 \mathrm{~Pa} \mathrm{~s}^{-1}$ at $850 \mathrm{hPa}$, which implied sinking rather than rising motion. Clearly, the sign obtained was incorrect at the windward side, mainly due to the positive tendency term. Without considering the advection term, the strongest rising motion occurred at $650 \mathrm{~m}$ with a value of $-0.096 \mathrm{~Pa} \mathrm{~s}^{-1}$, very different from that obtained at 850 $\mathrm{hPa}\left(0.079 \mathrm{~Pa} \mathrm{~s}^{-1}\right)$. Thus, $\omega$ estimate at Tungkang was unreliable, and the error was caused mostly from latent heat release, which violates the adiabatic assumption of the thermodynamic method.

At Lutao (lee side) where the adiabatic assumption is much more applicable, strong subsidence was obtained and its effect was one order of magnitude greater than that from horizontal advection (Table 2). It follows that $\theta$ increase (warming) seen at Lutao (Fig. 9c) was almost entirely caused by adiabatic subsidence. A vertical velocity of $0.228 \mathrm{~Pa} \mathrm{~s}^{-1}$ was estimated at $850 \mathrm{hPa}$ at 0000 UTC 8 June. The maximum $\omega$ from tendency term alone was $0.298 \mathrm{~Pa} \mathrm{~s}^{-1}$ at $1800 \mathrm{~m}$, also close to the value of $0.248 \mathrm{~Pa} \mathrm{~s}^{-1}$ at $850 \mathrm{hPa}$. The $0.228 \mathrm{~Pa} \mathrm{~s}^{-1}$ vertical velocity could sink roughly $550 \mathrm{~m}$ in $6 \mathrm{~h}$ and produce a corresponding warming of about $1.85 \mathrm{~K}$, close to the observed increase in $\theta$ values between 1 and 2 $\mathrm{km}$ at that time. Figure 9c also indicates an averaged warming close to $5 \mathrm{~K}$ for a column near $1.5-\mathrm{km}$ thick (1-2.5 km) from persisted subsidence for about $12 \mathrm{~h}$, and such a warming could lead to a hydrostatic response of SLP decrease of about $2.5 \mathrm{hPa}$ relative to the surrounding area, also in agreement with the observation (Fig. 5). Therefore, little doubt exists that subsidence warming at the lee side of southern CMR was the primary cause for mesolow formation in the current case, consistent with results obtained by Lin et al. (1992) and Sun and Chern (1993).

\section{b. Effect of latent heat release}

Since the mesolow formed primarily through leeside warming, difference in $\theta$ values between Jaohwa and Lutao can be used to indicate the strength of the mesolow. Since roughly $6 \mathrm{~h}$ were needed for an air parcel to travel from Jaohwa to Lutao at a speed of $10 \mathrm{~m} \mathrm{~s}^{-1}$ in the lower troposphere (cf. Fig. 3), we list in Table 3 pairs of $\theta$ values at fixed altitudes (from 0.5 to $3.0 \mathrm{~km}$ at intervals of $250 \mathrm{~m}$ ) at Jaohwa and Lutao $6 \mathrm{~h}$ apart. The increase in $\theta$ values in the lower troposphere from the upstream of CMR to the lee side was enhanced during the intensification and mature stages, reaching a maximum roughly between 0000 and 0600 UTC 8 June before weakening. Clear warming existed up to $3 \mathrm{~km}$, and the greatest $6-\mathrm{h} \theta$ increase in Table 3 is $4.3 \mathrm{~K}$ centered at $1.5 \mathrm{~km}$. The overall evolution given by Table 3 is in very good agreement with the life stages of the leeside mesolow.

It is well known that the high $\theta$ values on the lee side

FIG. 10. Streamline analyses at (a) $200 \mathrm{~m}$, (b) $400 \mathrm{~m}$, and (c) $600 \mathrm{~m}$ above ground for 0000 UTC 8 Jun 1987. (d)-(f) The same as (a)-(c) except for 0300 UTC 8 Jun. 
TABLE 3. Potential temperature $(\theta, \mathrm{K})$ between 0.5 and $3.0 \mathrm{~km}$ at intervals of $250 \mathrm{~m}(h$; $\mathrm{m})$ at Jaohwa (RCJH) and Lutao (46780) for indicated time pairs (UTC) $6 \mathrm{~h}$ apart. One (two) asterisk(s) indicates Lutao minus Jaohwa difference in $\theta$ of at least $2.0 \mathrm{~K}$ (4.0 K) at the height indicated.

\begin{tabular}{|c|c|c|c|c|c|c|c|c|c|c|c|c|}
\hline \multirow{3}{*}{$\begin{array}{c}\text { Stage } \\
\text { Time } \\
\text { Station }\end{array}$} & \multirow{3}{*}{$\begin{array}{c}1500 \\
\text { RCJH }\end{array}$} & \multicolumn{2}{|c|}{ Intensification } & \multicolumn{4}{|c|}{ Mature } & \multicolumn{3}{|c|}{ Weakening } & \multirow{3}{*}{$\begin{array}{c}0600 \\
\text { RCJH }\end{array}$} & \multirow{3}{*}{$\begin{array}{c}1200 \\
46780\end{array}$} \\
\hline & & 2100 & 1800 & 0000 & 2100 & 0300 & 0000 & 0600 & 0300 & 0900 & & \\
\hline & & 46780 & $\mathrm{RCJH}$ & 46780 & $\mathrm{RCJH}$ & 46780 & $\mathrm{RCJH}$ & 46780 & $\mathrm{RCJH}$ & 46780 & & \\
\hline \multicolumn{13}{|l|}{$h$} \\
\hline 3000 & 312.6 & 312.9 & 312.4 & 313.8 & 313.3 & 313.6 & 313.3 & 314.2 & 313.1 & 314.2 & 313.1 & 313.5 \\
\hline 2750 & 311.5 & 311.8 & 310.7 & *312.7 & 311.6 & 312.7 & 311.7 & 313.5 & 311.5 & 313.0 & 311.1 & 312.2 \\
\hline 2500 & 310.4 & 309.5 & 309.6 & *311.9 & 309.8 & 311.7 & 310.4 & *312.6 & 310.4 & 311.7 & 310.2 & 310.9 \\
\hline 2250 & 309.0 & 308.3 & 308.2 & *310.8 & 308.2 & *310.8 & 309.1 & *311.8 & 309.1 & 310.4 & 309.0 & 309.6 \\
\hline 2000 & 307.2 & 307.1 & 306.9 & *309.3 & 306.5 & *309.8 & 307.2 & *310.9 & 308.2 & 309.2 & 307.5 & 308.3 \\
\hline 1750 & 306.0 & 306.9 & 306.3 & 307.7 & 305.1 & *308.9 & 306.2 & *310.1 & 306.8 & 308.0 & 305.9 & 306.9 \\
\hline 1500 & 304.7 & 305.7 & 305.4 & 306.6 & 304.1 & *307.9 & 305.0 & $* * 309.3$ & 305.7 & 306.8 & 304.5 & 305.7 \\
\hline 1250 & 303.7 & 304.6 & 304.1 & 305.5 & 303.2 & $* * 307.2$ & 304.5 & *308.1 & 304.6 & 304.7 & 303.0 & 304.4 \\
\hline 1000 & 301.9 & 303.5 & 303.0 & 304.5 & 302.5 & $* 305.5$ & 304.1 & 305.5 & 303.3 & 303.8 & 302.0 & 302.9 \\
\hline 750 & 301.1 & 301.9 & 302.4 & 302.2 & 301.4 & *303.6 & 302.3 & 302.4 & 302.0 & 302.9 & 300.8 & 301.5 \\
\hline 500 & 299.5 & 301.1 & 300.1 & 301.7 & 300.8 & 301.4 & 301.1 & 302.3 & 301.5 & 302.0 & 299.7 & 300.5 \\
\hline
\end{tabular}

can come from two sources. The first is from adiabatic subsidence of air originally at a higher level, while the second source is from condensational heating during forced uplift along the windward slope. The skew $T-$ $\log p$ diagram of Jaohwa at 2100 UTC 7 June (Fig. 11a) showed that the upstream air was conditionally unstable and very moist in the lower to middle troposphere, and the relative humidity was $100 \%$ from 0.8 to $1.5 \mathrm{~km}$. The temperature and moisture profiles of Tungkang at 0000 UTC 8 June (Fig. 11b) were quite similar to that of Jaohwa, also with high relative humidity ( $\geq 94 \%$ ) below $1500 \mathrm{~m}$ (c.f. Fig. 8e). The profiles at Lutao at 0600 UTC in the early weakening stage, on the other hand, clearly showed a much drier condition with a strong inversion located at $850-1150 \mathrm{~m}$ produced by subsidence warming (Fig. 11c). It was also clear that at this time the leeside sinking occurred from 1150 up to about $3000 \mathrm{~m}$. Based on kinetic and potential energy argument without considering pressure variation, Sheppard (1956) suggested that the maximum vertical displacement of an air parcel at the windward side would be limited by $U / N$, which is roughly $1 \mathrm{~km}$ in our case ( $U \approx 10 \mathrm{~m} \mathrm{~s}^{-1}$ and $N \approx 10^{-2} \mathrm{~s}^{-1}$ ). Although pressure variation should not be neglected, this prediction empirically remains close to observations (Baines 1995, section 6.6.3; Smith 1990). Together with the significant blocking up to at least $600 \mathrm{~m}$ (Fig. 10) and a height of CMR of about $1.8 \mathrm{~km}$ near $22.5^{\circ} \mathrm{N}$, if we assumed an air parcel to rise from 0.8 to $1.8 \mathrm{~km}$ at the windward side, then its $\theta$ value would increase by roughly $4 \mathrm{~K}$ following a pseudo-adiabatic process using the Tungkang sounding in Fig. 11b. At levels slightly above, the air was likely to rise less than $1 \mathrm{~km}$, and a smaller lifting, for example, from 1.5 to $2.0 \mathrm{~km}$, would increase $\theta$ by about $2 \mathrm{~K}$. By averaging these two values and also considering mixing that acts to reduce $\theta$ increase, we estimate the increase in $\theta$ due to condensational heating in the present case would be in general less than $2.5 \mathrm{~K}$, or about $58 \%$ of the biggest $\theta$ difference between two sides of the CMR (Table 3). It should be noted here that this estimate is very rough, as data at a sufficiently high spatial-temporal resolution were not available.

Holton (1992, p. 388) provides another method to estimate the effect of latent heat release from precipitation rates independently. With a specified vertical heating profile and assuming that $2 \mathrm{~h}$ were needed for an air parcel to travel from the coast to the ridge of the CMR, we can estimate the warming in the lower troposphere along the windward slope, and compare it with the total $\theta$ increase in Table 3. By using Fig. 6, the averaged 2-h rainfall amount was computed for a rectangular area from $120.2^{\circ}$ to $120.8^{\circ} \mathrm{E}, 22.4^{\circ}$ to $23.2^{\circ} \mathrm{N}$ (excluding about $9 \%$ of ocean area due to lack of data) and the associated latent heating was distributed evenly between 900 and $200 \mathrm{hPa}$. Estimates for two periods of rainfall, one from 2300 UTC 7 June to 0100 UTC 8 June and the other from 0200 to 0400 UTC 8 June, were performed, and the resulted average warming of the 700-900-hPa layer is summarized in Table 4. From 2300 UTC 7 June to 0100 UTC 8 June, the averaged rainfall amount of $3.73 \mathrm{~mm}$ caused roughly $1.27 \mathrm{~K}$ of $\theta$ increase in the lower troposphere, which accounted for $45.8 \%$ of the $\theta$ difference between upstream environment and the lee side ( $6 \mathrm{~h}$ apart, between $2100 \mathrm{UTC}$ 7 June and 0300 UTC 8 June). Similarly, the rainfall of $5.57 \mathrm{~mm}$ from 0200 to 0400 UTC caused a warming of about $1.98 \mathrm{~K}$, or $67.8 \%$ of the $\theta$ difference. The averaged percentage of $56.8 \%$ for the two periods is quite close to our earlier estimate of $58 \%$, and this greatly increases our confidence in these estimates. Therefore, it is reasonable to conclude that latent heat release at the windward side in the present case, at its peak, contributed about $55 \%-60 \%$ of the total warming, and the remaining must come from subsidence from a higher level. Of course, in cases where the precipitation is less, latent heat release would play a less important role in raising $\theta$ values at the windward side.

Figure 12 presents a schematic illustration that de- 
(a)

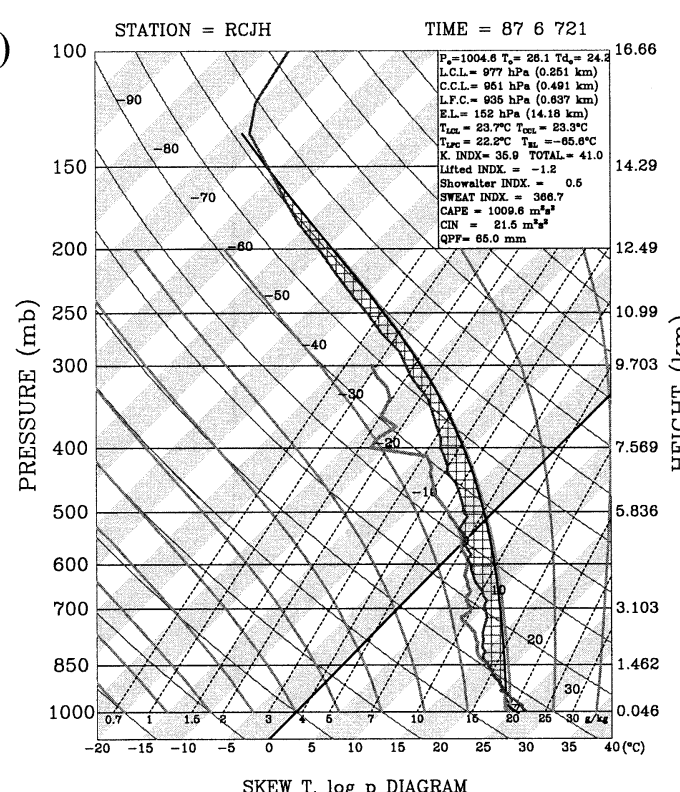

(b)

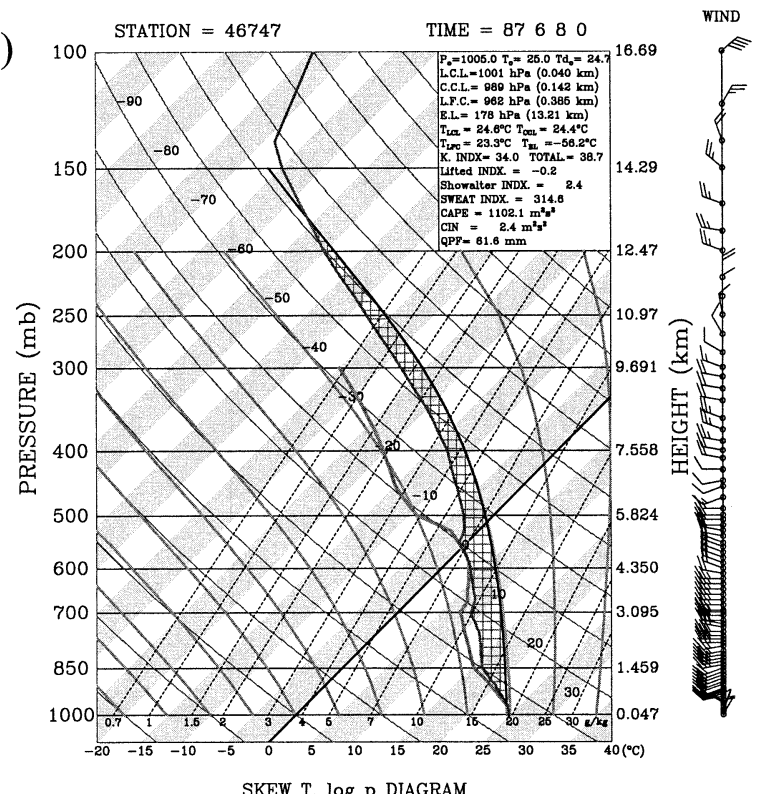

(c)

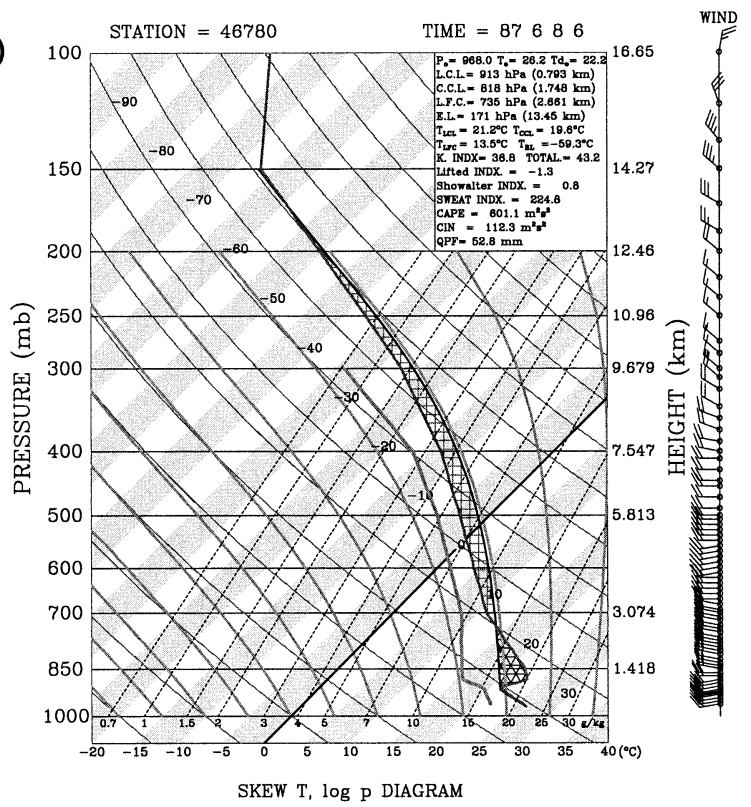

FIG. 11. The skew $T-\log p$ diagram of (a) Jaohwa at 2100 UTC 7 Jun, (b) Tungkang at 0000 UTC 8 Jun, and (c) Lutao at 0600 UTC 8 Jun.

scribes the processes observed in this case. As the Meiyu front approached and prevailing southwesterly winds strengthened, the low-level flow was blocked by the CMR and split into two branches, producing LLJs in areas both northwest and southeast of the terrain. Flow at higher levels above the splitting layer but below the mountain ridge climbed along the windward side of mountain and produced precipitation, and then sank on the lee side. Air parcels at yet higher levels above the terrain also sank directly on the leeside. The sinking led to the formation of the mesolow through adiabatic warming, and the bottom of the subsidence was near $1000 \mathrm{~m}$.

It is likely that a positive feedback mechanism also existed in this case. While the low-level flow remained blocked during the entire analyzed period, the strengthening of the prevailing southwesterly flow ahead of the Mei-yu front (along with an increase in both Fr and Ro) led to a weakening of the blocking and a reduction of the depth of the splitting layer. This allowed upstream air from an originally lower elevation (and thus containing more moisture) to climb over the mountain, 
TABLE 4. Estimated effect of latent heat release at the windward side for two 2-h periods 2300 UTC 7 Jun-0100 UTC 8 Jun and 02000400 UTC 8 Jun and their comparison with 6-h $\theta$ increase (averaged over 1-3 km) from the windward side to lee side listed in Table 3. The 6-h periods selected were 2100 UTC 7 Jun-0300 UTC 8 Jun and 0000-0600 8 Jun, respectively. See text for further explanation of the method.

\begin{tabular}{lrr}
\hline \hline \multicolumn{1}{c}{ 3 h time period } & $2300-0100$ UTC & 0200-0400 UTC \\
7-8 Jun & Jun & 4.65 \\
Averaged 3-h rainfall (mm) & 3.73 & 5.57 \\
Latent energy released (MJ) & 9.33 & 13.93 \\
Averaged 700-900 hPa warming (K) & 1.27 & 1.98 \\
Mean 1-3 km $\sigma$ increasing (K) for the & 2.77 & 2.92 \\
6-h period indicated in parentheses & $(2100-0300$ UTC) & (0000-0600 UTC) \\
Percentage & $45.8 \%$ & $67.8 \%$ \\
\hline
\end{tabular}

which in turn produced orographic precipitation and release of latent heat, leading to further decrease in $N$ and increase in Fr. This sequence provided a positive feedback to reinforce the "flow over" regime, as opposed to the "flow around" regime. It is in agreement with the observations (Fig. 10), and may partially explain the abundant rainfall that occurred in the weakening stage (Fig. 6c).

\section{c. Cyclone vorticity and mesovortex formation}

Due to the confluence and subsequent acceleration of airflow, strong west-southwest wind was observed at Lanyu Island and produced shear vorticity to the southeast of Taiwan (Fig. 5). In natural coordinates, relative vorticity $(\zeta)$ is

$$
\zeta=\frac{V}{R_{s}}-\frac{\partial V}{\partial n}
$$

where $R_{s}$ is the radius of streamline curvature. Using the observations at 0100 UTC 8 June during the mature stage (Fig. 5e) with a west-southwest wind $\left(240^{\circ}\right)$ of 15 $\mathrm{m} \mathrm{s}^{-1}$ at Lanyu, a west-northwest wind $\left(300^{\circ}\right)$ of $5 \mathrm{~m}$ $\mathrm{s}^{-1}$ at Hengchun, an east wind of $2.5 \mathrm{~m} \mathrm{~s}^{-1}$ at Taitung, and $R_{s}$ taken to be $100 \mathrm{~km}$ (estimated based on assumed

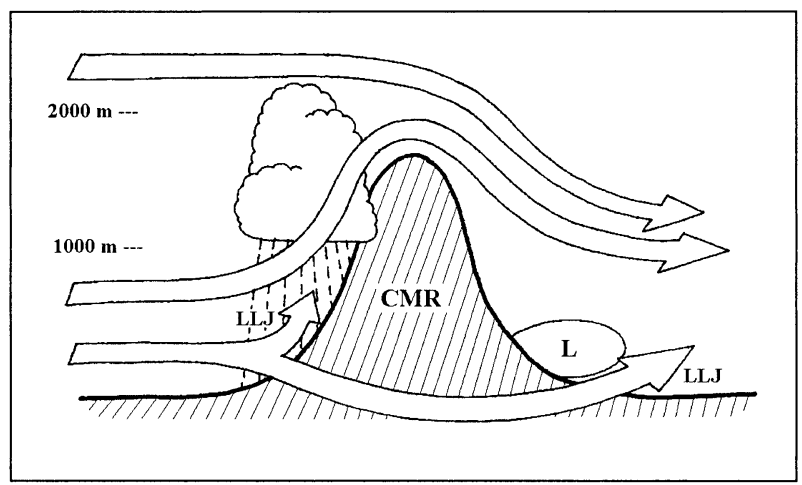

FIG. 12. Schematic illustration of processes in the present case. Thick solid line and hatching represent the terrain of Taiwan, and open arrows represent airflow at different levels. Clouds and precipitation were observed along the windward (west) side of the CMR, while the mesolow was produced on the lee side (east side) through adiabatic warming. wind directions at Hengchun and Lanyu), shear and curvature vorticity near Lanyu could be roughly estimated to be about 2.0 and $1.5 \times 10^{-4} \mathrm{~s}^{-1}$, respectively. The total $\zeta$ was thus about $3.5 \times 10^{-4} \mathrm{~s}^{-1}$, similar to the magnitude obtained by Sun and Chern (1993) for the IOP-2 case. With observations at a higher resolution, shear vorticity can in fact be dramatically larger, as a value near $2.0 \times 10^{-3} \mathrm{~s}^{-1}$ was obtained by Smith and Grubišić (1993) along the shear zone in the wakes of the Island of Hawaii using airplane flight data.

Several possible mechanisms have been suggested for the formation of lee vortices, including boundary layer separation (e.g., Hunt and Snyder 1980), tilting of baroclinic vorticity (Smolarkiewicz and Rotunno 1989; Rotunno et al. 1999), and vortex stretching based on conservation of potential vorticity (Kuo and Chen 1990). Sun and Chern (1993) performed a vorticity budget analysis on the TAMEX IOP- 2 case, and concluded that the tilting effect was important to the generation of $\zeta$ over the CMR, while stretching was responsible for the vorticity associated with the leeside mesolow over the ocean. In our present case during IOP-8, the mesovortex formed along the southeast coast of Taiwan, about 90 $\mathrm{km}$ away from the low center, and remained largely stationary, and thus stretching was unlikely to be the primary mechanism for its formation. Further investigations are needed to clarify the contribution from tilting effect, the role played by the so-called corner effect induced locally by the terrain of Hengchun Peninsula, as well as the interaction between LLJs due to terrain blocking and local circulations such as land-sea and mountain-valley breezes. Another interesting aspect is the interaction among prevailing flow, terrain, and frontal circulation. As seen in the weakening stage of the current case, the approach of a surface Mei-yu front east of Taiwan, with sufficient cyclonic vorticity, appeared to cause the leeside mesolow to merge with the front and transform into a migratory mesocyclone along the front. Since the mesolow, forming through subsidence warming, is essentially a stationary system, such a transformation and the processes involved (such as the role of the front and the modulation of frontal flow by terrain) merit further study. 


\section{Summary and concluding remarks}

An observational case study was performed on a leeside mesolow/mesocyclone event occurred 8 June 1987 during IOP-8 of TAMEX. Detailed mesoscale analyses of SLP and surface streamline were carried out, and time-height cross sections at stations representing the windward side and the lee side were constructed to document the features and evolution of the case using data collected during the TAMEX program. The Froude number (Fr) and Rossby number (Ro) were computed and vertical velocity estimated using the thermodynamic method to facilitate discussion on the mechanism(s) responsible for the formation and maintenance of the case. A rough estimate on the effect of latent heat release along the windward slope was also carried out. Finally, a schematic illustration including the major processes found in the case is presented.

In summary, the current case developed as prevailing west-southwest winds strengthened and interacted with the high terrain of Taiwan, under Fr increasing from below 0.3 to over 0.5 . A quasi-stationary mesolow formed to the southeast of Taiwan with no closed circulation through most of its life stages until passage of the Mei-yu front. A stationary and localized mesovortex also formed about $90 \mathrm{~km}$ southwest of the low center, with little adjustment in location between the two. Thus, a geostrophic relationship did not exist, consistent with the Ro values of near 1.5-3.0.

Air parcels moved both around the terrain of CMR (at lower levels) and climbed over it (at higher levels). Those over the mountain subsided at the leeside and produced the mesolow through adiabatic warming, which was strongest between 1 and $2 \mathrm{~km}$. Latent heat release at the windward side is estimated to contribute a maximum of about $55 \%-60 \%$ of the total increase in potential temperature, while the remaining is from subsidence from a higher level. Lower-level flow blocked by terrain led to formation of a LLJ to the southeast of Taiwan, and provided background shear vorticity in the region. The primary mechanism for the formation of the mesovortex was likely different from that for the mesolow, since the two were not collocated. As the Meiyu front moved to the southeast of Taiwan and provided cyclonic vorticity, the leeside mesolow merged with the front and transformed into a migratory mesocyclone along the front.

Further studies are needed to clarify the complex interaction between prevailing flow and terrain of the CMR, and the mechanism(s) for the formation of the mesovortex and its interaction with the low, as well as with local circulation systems such as the land-sea and mountain-valley breezes. To remedy the problem caused by the lack of observational data in the region, exploration of possible uses of other nonconventional data, such as the QuikSCAT ocean wind data becoming available recently, appears to be also necessary in future studies of the leeside mesolow/mesovortex to the southeast of Taiwan.

Acknowledgements. The authors wish to express their sincere appreciation to the anonymous reviewers for giving many valuable comments and suggestions, which helped greatly to improve the quality of the manuscript. Thanks are also to Mr. J. S. Yang for drafting some of the figures. This study was supported by research Grant NSC-91-211-M-002-030 of Taiwan, Republic of China.

\section{REFERENCES}

Baines, P. G., 1995: Topographic effects in stratified flows. Cambridge University Press, $482 \mathrm{pp}$.

Bell, G. D., and L. F. Bosart, 1988: Appalachian cold-air damming. Mon. Wea. Rev., 116, 137-161.

Bougeault, P., and Coauthors, 2001: The MAP Special Observing Period. Bull. Amer. Meteor. Soc., 82, 433-462.

Chen, G. T. J., 1991: Observational study on mesoscale features in Taiwan Mei-Yu season (I). Research Rep. NTUATM-1991-001, (in Chinese with English abstract). Department of Atmospheric Sciences, National Taiwan University, 136 pp.

__ 1992a: Mesoscale features observed in Taiwan Mei-Yu season. J. Meteor. Soc. Japan, 70, 497-516.

_ 1992 b: Observational study on mesoscale features in Taiwan Mei-Yu season (II). Research Rep. NTUATM-1992-001, (in Chinese with English abstract). Department of Atmospheric Sciences, National Taiwan University, 185 pp.

Crook, N. A., T. L. Clark, and M. W. Moncrieff, 1990: The Denver Cyclone. Part I: Generation in low Froude number flow. J. Atmos. Sci., 47, 2725-2742.

Davis, C. A., 1997: Mesoscale anticyclone circulations in the lee of the central Rocky Mountains. Mon. Wea. Rev., 125, 2838-2855.

Ferber, G. K., and C. F. Mass, 1990: Surface pressure perturbations produced by an isolated mesoscale topographic barrier. Part II: Influence on regional circulations. Mon. Wea. Rev., 118, $2597-$ 2606.

Forbes, G. S., R. A. Anthes, and D. W. Thompson, 1987: Synoptic and mesoscale aspects of an Appalachian ice storm associated with cold-air damming. Mon. Wea. Rev., 115, 564-591.

Georgelin, M., E. Richard, and M. Petididier, 1996: The impact of diurnal cycle on a low-Froude number flow observed during the PYREX Experiment. Mon. Wea. Rev., 124, 1119-1131.

Holton, J. R., 1992: An Introduction to Dynamic Meteorology. 3d ed. Academic Press, $511 \mathrm{pp}$.

Hunt, J. C. R., and W. H. Snyder, 1980: Experiments on stably and neutrally stratified flow of a model three-dimensional hill. $J$. Fluid Mech., 96, 671-704.

Kuo, Y.-H., and G. T. J. Chen, 1990: Taiwan Area Mesoscale Experiment. An Overview. Bull. Amer. Meteor. Soc., 71, 488-503.

Lee, T.-Y., Y.-Y. Park, and Y.-L. Lin, 1998: A numerical modeling study of mesoscale cyclogenesis to the east of the Korean peninsula. Mon. Wea. Rev., 126, 2305-2329.

Li, J., and Y.-L. Chen, 1998: Barrier jets during TAMEX. Mon. Wea. Rev., 126, 959-971.

Lin, Y.-L., N.-H. Lin, and R. P. Weglarz, 1992: Numerical modeling studies of lee mesolows, mesovortices and mesocyclones with application to the formation of Taiwan mesolows. Meteor. Atmos. Phys., 49, 43-67.

Manins, P. C., and B. L. Sawford, 1982: Mesoscale observations of upstream blocking. Quart. J. Roy. Meteor. Soc., 108, 427-434.

Peng, M. S., S.-W. Li, S. W. Chang, and R. T. Williams, 1995: Flow over mountains: Coriolis force, transient troughs and three dimensionality. Quart. J. Roy. Meteor. Soc., 121, 593-613.

Reisner, J. M., and P. K. Smolarkiewicz, 1994: Thermally forced low Froude number flow past three-dimensional obstacles. J. Atmos. Sci., 51, 117-133. 
Rotunno, R., V. Grubisic, and P. K. Smolarkiewicz, 1999: Vorticity and potential vorticity in mountain wakes. J. Atmos. Sci., 56, 2796-2810.

Schär, C., and R. B. Smith, 1993: Shallow-water flow past isolated topography. Part I: Vorticity production and wake formation. $J$. Atmos. Sci., 50, 1373-1400.

Sheppard, P. A., 1956: Airflow over mountains. Quart. J. Roy. Meteor. Soc., 82, 528-529.

Smith, R. B., 1980: Linear theory of stratified hydrostatic flow past an isolated mountain. Tellus, 32, 348-364.

-, 1982: Synoptic observations and theory of orographically disturbed wind and pressure. J. Atmos. Sci., 39, 60-70.

1989: Hydrostatic airflow over mountains. Advances in Geophysics, Vol. 31, Academic Press, 1-41.

- 1990: Why can't stably stratified air rise over high ground? Atmospheric Processes over Complex Terrain, W. Blumen, Ed., Meteor. Monogr., No. 23, Amer. Meteor. Soc., 105-107.
_ and V. Grubišić, 1993: Aerial observations of Hawaii’s wake. J. Atmos. Sci., 50, 3728-3750.

Smolarkiewicz, P. K., and R. Rotunno, 1989: Low Froude number flow past three-dimensional obstacles. Part I: Baroclinically generated lee vortices. J. Atmos. Sci., 46, 1154-1164.

— , R. Rasmussen, and T. L. Clark, 1988: On the dynamics of Hawaiian cloud band: Island forcing. J. Atmos. Sci., 45, 18721905.

Sun, W.-Y., and J.-D. Chern, 1993: Diurnal variation of lee vortices in Taiwan and the surrounding area. J. Atmos. Sci., 50, 34043430.

Wang, S. T., 1990: Subjective mesoscale analysis data during Taiwan Area Mesoscale Experiment (TAMEX). Vol. 1, Original Surface Map Collection during TAMEX Intensive Observing Periods (IOPs), Central Weather Bureau of ROC, 479 pp. [Available from the Dept. of Atmospheric Sciences, National Taiwan University, Taipei, Taiwan, ROC.] 